OPEN ACCESS

Edited by:

Jianrong Qiu,

South China University of Technology,

China

Reviewed by:

Jinjun Ren,

Shanghai Institute of Optics and Fine

Mechanics (CAS), China

Laeticia Petit,

Tampere University of Technology,

Finland

${ }^{*}$ Correspondence:

Morten M. Smedskjaer mos@bio.aau.dk

Specialty section: This article was submitted to Glass Science,

a section of the journal Frontiers in Materials

Received: 09 November 2016 Accepted: 26 January 2017 Published: 16 February 2017

Citation:

Kapoor S, Wondraczek L and Smedskjaer MM (2017) PressureInduced Densification of Oxide Glasses at the Glass Transition.

Front. Mater. 4:1.

doi: 10.3389/fmats.2017.00001

\section{Pressure-Induced Densification of Oxide Glasses at the Glass Transition}

\author{
Saurabh Kapoor ${ }^{1}$, Lothar Wondraczek ${ }^{2}$ and Morten M. Smedskjaer ${ }^{1 *}$ \\ ${ }^{1}$ Department of Chemistry and Bioscience, Aalborg University, Aalborg, Denmark, ${ }^{2}$ Otto Schott Institute of Materials \\ Research, Friedrich Schiller University of Jena, Jena, Germany
}

Densification of oxide glasses at the glass transition offers a novel route to develop bulk glasses with tailored properties for emerging applications. Such densification can be achieved in the technologically relevant pressure regime of up to 1 GPa. However, the present understanding of the composition-structure-property relationships governing these glasses is limited, with key questions, e.g., related to densification mechanism, remaining largely unanswered. Recent advances in structural characterization tools and high-pressure apparatuses have prompted new research efforts. Here, we review this recent progress and the insights gained in the understanding of the influence of isostatic compression at elevated temperature (so-called hot compression) on the compositionstructure-property relationships of oxide glasses. We focus on compression at temperatures at or around the glass transition temperature $\left(T_{g}\right)$, with relevant comparisons made to glasses prepared by pressure quenching and cold compression. We show that permanent densification at $1 \mathrm{GPa}$ sets in at temperatures above $0.7 \mathrm{~T}_{\mathrm{g}}$ and the degree of densification increases with increasing compression temperature and time, until attaining an approximately constant value for temperatures above $T_{\mathrm{g}}$. For glasses compressed at the same temperature/pressure conditions, we demonstrate direct relations between the degree of volume densification and the pressure-induced change in micromechanical properties such as hardness, elastic moduli, and extent of the indentation size effect across a variety of glass families. Finally, we review the results on relaxation behavior of hot-compressed glasses. In summary, all the pressure-induced changes in the structure and properties exhibit strong composition dependence. The experimental results highlight new opportunities for future investigation and identify research challenges that need to be overcome to advance the field.

\footnotetext{
Keywords: glass, compression, structure-properties relationships, indentation, NMR spectroscopy, densification, relaxation, review
}

\section{INTRODUCTION}

During the last century, oxide glasses are being increasingly used for decorative articles, optics, architectural purposes (from windows to whole glass facades), glassware for chemical reactions, consumer electronic devices, telecommunication applications, etc. The major advantage of glasses is their ability to accommodate essentially any element from the Periodic Table in their amorphous state, thus providing enormous flexibility to tailor and optimize their performances with respect to different technological applications. This flexibility has consequently led to significant research 
efforts in the understanding of composition-structure-property relationships in oxide glasses to advance the field of glass science from simple trial-and-error approaches (Wondraczek and Mauro, 2009; Mauro and Zanotto, 2014).

Chemical composition variation and thermal treatments are well-known methods for tailoring the glass structure and properties, but densification of glasses at high pressure presents a more recent alternative. The application of pressure enables precise tuning of the interatomic distances and bonding patterns in a material, providing an additional degree of freedom compared to varying composition or temperature alone. Moreover, from an industrial perspective, high-pressure treatment of oxide glasses at elevated temperature can induce permanent property changes, which are preserved upon quenching to the ambient conditions (Smedskjaer et al., 2014b). Furthermore, pressure-induced changes in the structure and properties of silicate glasses and glass-forming liquids are of significant interest to the geological community. Understanding of the transport (e.g., viscosity and diffusivity) and thermodynamic properties (e.g., configurational entropy, heat capacity, activity coefficient of silica, element partitioning coefficient) enhances the understanding of the chemical and physical evolution of the Earth into its current stratified structure from magma oceans in the early Earth history (Wolf and McMillan, 1995; Poe et al., 1997; Lee, 2005; Mysen and Richet, 2005; Allwardt et al., 2007; Lee et al., 2008; Spera et al., 2009). High-pressure studies also improve the understanding of geochemical processes involving magmas, such as melting, migration, and emplacement of melts in the Earth's surfaces and interiors (Angell et al., 1982; Navrotsky et al., 1982; Kushiro, 1983; Shimizu and Kushiro, 1984; Neuville and Richet, 1991; Bottinga and Richet, 1995; Toplis et al., 1997a; Poe et al., 2001; Tinker et al., 2003).

Permanent densification of glass is conventionally achieved by cold compression at pressures above 8-10 GPa (Mackenzie, 1963a; Champagnon et al., 2008; Martinet et al., 2015). This method allows experiments to be performed in situ in the high-pressure regime at room temperature and has led to interesting results on pressure-induced structural changes in glasses (Grimsditch et al., 1996; Lee et al., 2005a). However, only small sample specimens can be processed, and subsequent characterization of macroscopic properties (e.g., mechanical properties) is often impossible (Sakka and Mackenzie, 1969; McMillan, 2002). An alternative approach to obtain permanent densification is by pressurization of glasses at elevated temperature, which can be roughly divided into pressure quenching (Lee, 2010) and hot compression (Mackenzie, 1964; Smedskjaer et al., 2014a) experiments. The former refers to quenching a glass-forming liquid under high pressure, while the latter involves heating the glass under high pressure up to or around the glass transition temperature $\left(T_{\mathrm{g}}\right)$. Using pressure quenching or hot compression, permanent densification is achieved at much lower pressures compared to room temperature experiments (Wondraczek et al., 2007a, 2010; Yue et al., 2007; Wu et al., 2009), enabling the preparation of larger sized specimens. In addition, structural characterization at ambient conditions involves fewer assumptions as there are less spectroscopic uncertainties compared to measurements performed in situ at extreme conditions, such as temperature and pressure effects on infrared
(IR) absorption coefficients and Raman scattering cross-sections (McMillan and Wolf, 1995) and anharmonic vibrations (Brown et al., 1995; Daniel et al., 1995; Chen et al., 2011). The subsequent discussion will focus on recovered oxide glasses that have been compressed at temperatures ranging from sub- $T_{\mathrm{g}}$ to $T_{\mathrm{g}}$ at high pressure, with relevant comparison made with other densification methods.

The pioneering studies reporting the impact of compression at temperatures at or above $T_{\mathrm{g}}$ suggested a permanent (inelastic) increase in density (Mackenzie, 1964), which prompted a number of investigations to understand the influence of hot compression on the structure and properties of glasses. Despite the importance and significant efforts to understand the influence of pressure (Mackenzie, 1964; Chason and Spaepen, 1988; Wondraczek et al., 2007b; Wu et al., 2009; Chen et al., 2011; Smedskjaer et al., 2014a,b; Aakermann et al., 2015; Svenson et al., 2016c), our understanding of the composition-structure-property relationships governing these oxide glasses at high pressure and temperature is still at a premature stage. This has resulted in considerable research in the glass community in recent years, particularly related to the structure of glasses quenched from high temperature and those compressed at room temperature (Lee and Stebbins, 2003; Allwardt et al., 2004, 2005a; Lee et al., 2005a; Lee, 2010; Martinet et al., 2015). Recently, more studies have also focused on the structure-property relationship in glasses compressed around $T_{\mathrm{g}}$, unveiling the detailed pressure-induced changes in the network topology and properties of oxide glasses at high pressure (Wondraczek et al., 2007b, 2010; Reibstein et al., 2011; Striepe et al., 2013; Smedskjaer et al., 2014a,b; Aakermann et al., 2015; Østergaard et al., 2015; Bechgaard et al., 2016; Svenson et al., 2016c).

In this review, we summarize the recent progress in the analysis of pressure-induced changes in the structure and properties of oxide glasses. We do not attempt to provide an extensive review of the structure of oxide glasses under pressure, as excellent accounts of earlier studies on the structure of oxide glasses/ melts at high pressure can already be found in the literature (Lee, 2010; Chen et al., 2011). First, we outline the experimental conditions required for pressure generation. Subsequently, we present the structures of oxide glasses at high pressure, focusing on the pressure-induced changes in the short-range order (SRO) and medium-range order (MRO). Then we discuss about the pressure-induced changes in the macroscopic properties of the glasses and the stability of these pressure-induced changes about ambient pressure annealing. Finally, we discuss new opportunities for future research and identify specific research challenges that need to be overcome to advance the field.

\section{HIGH-PRESSURE HIGH-TEMPERATURE (HP-HT) DEVICES}

High-pressure high-temperature devices have evolved over time. In the early studies of oxide glasses compressed at different pressures at $T_{\mathrm{g}}$ or sub- $T_{\mathrm{g}}$ temperatures, Mackenzie used the "Belt" apparatus that can apply pressure up to $10 \mathrm{GPa}$ and temperature can reach up to $2273 \mathrm{~K}$ (Hall, 1960). Pyrophyllite and hydrous 
aluminum silicate are used as pressure-transmitting mediums, and the sample is heated by passage of an electric current through a metal or graphite tube containing the sample. In addition, multianvil apparatuses (MAA) have been fundamental for progress in high-pressure research. As for other techniques, the function of MAA is based on the principle that pressure $(P)$ is equal to an applied force $(F)$ divided by the area $(A)$ over which it is applied. Therefore, pressure can be increased by reducing the area over which the force is applied. The anvils used in MAA are composed of very hard materials [such as tungsten carbide (WC) or sintered polycrystalline diamond or boron nitride $(\mathrm{BN})]$ and are designed to have a large surface area on one side and a relatively small surface area on the side that contacts the pressurized volume. A review of the developments and advances in MAA can be found elsewhere (Ito, 2007). The octahedral anvil method has been used in several studies involving pressure quenching and hot compression (Inamura et al., 2001), in which an octahedral assembly of WC anvils can generate a maximum pressure up to $25 \mathrm{GPa}$ at temperatures up to $2,500 \mathrm{~K}$. When operated using sintered diamond anvils, it can produce pressures above $30 \mathrm{GPa}$ (Lee, 2010). Other studies have used the piston cylinder apparatus invented by Boyd and England with talc, pyrophyllite, and BN as a pressuretransmitting medium (Boyd and England, 1960; Guerette et al., 2015). Piston cylinder devices generate pressure by compressing a sample assembly inside a pressure vessel. The pressure vessel is closed at one end by a rigid plate with a small hole for the thermocouple to pass through, and the piston is advanced into the cylinder from the other end. This experimental setup can be used to generate a pressure of about $5 \mathrm{GPa}$ at a temperature up to 2,023 K (Boyd and England, 1960).

Our recent studies on hot compression have made use of gas chamber vessels to enable isostatic compression (Wondraczek et al., 2007b, 2010; Wu et al., 2009; Smedskjaer et al., 2014a, 2015). This approach can use a vertically positioned, technological gas pressure chamber with a relatively large internal diameter above $5 \mathrm{~cm}$ (allowing crucible with working volume $>20 \mathrm{~cm}^{3}$ ) (Figure 1), similar to hot-isostatic pressure-sintering, which is a common tool in the processing of ceramics. A multizone cylindrical graphite furnace is placed inside the gas pressure reactor, and the temperature is monitored during experiments using thermocouples, which are arranged along the furnace and coupled with the input power control electronic systems. The pressure is measured by manganin gages positioned in the low-temperature zone of the reactor. This approach enables permanent densification of bulk samples (e.g., $10 \mathrm{~mm} \times 10 \mathrm{~mm} \times 5 \mathrm{~mm}$ ) at modest pressures (1-2 GPa). Nitrogen is typically used as the compression medium, since its permeability in most oxide glasses is low compared to, e.g., helium (Sato et al., 2011).

\section{PERMANENT DENSIFICATION: ROLE OF TEMPERATURE}

To our knowledge, the first studies on compression of glasses at room temperature were conducted around 1929 by Tammann and Jenckel (1929). Compression of glasses at pressures around $8 \mathrm{GPa}$ at room temperature or temperatures significantly below

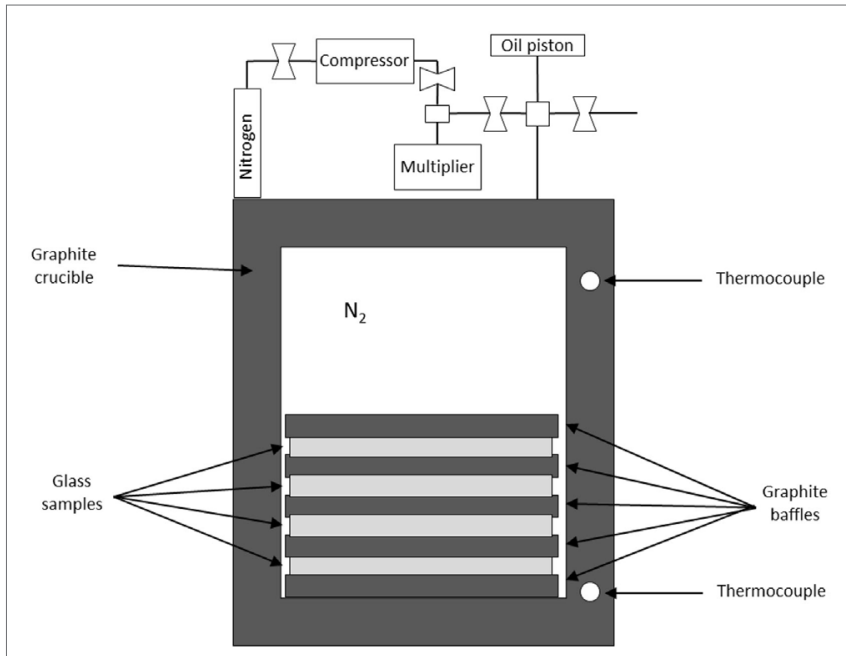

FIGURE 1 | Schematic illustration of the gas pressure vessel method for hot compression.

$T_{\mathrm{g}}$ was found to result in elastic densification or a "metastable" densification, where ambient pressure annealing at relatively low temperatures can relax the glass to its precompressed state due to the short relaxation times and lower activation energy (Mackenzie, 1963a; Sakka and Mackenzie, 1969). For example, upon room temperature densification of boron oxide glass, the density decreases with time after pressure release (Mackenzie, 1963b). Glasses densified at elevated temperature (i.e., around $T_{\mathrm{g}}$ ) exhibit permanent (stable) densification if the compression duration is long enough for the glass to structurally equilibrate to the high-pressure environment. Thus, densification of various oxide glasses at room temperature can be unstable in comparison to glasses compressed at higher temperatures. Furthermore, Yamada et al. (2010) classified the temperature-dependent densification behavior of $\mathrm{Mg}$-silicate glass compressed up to $8.5 \mathrm{GPa}$ at $T_{\mathrm{g}}$ in three different regions (Figure 2). Region 1 is the low-temperature region, where the pressure-induced changes in density are elastic (reversible). Region 2 corresponds to a mid-temperature region, in which the increase in temperature results in an abrupt increase in the degree of densification. These pressure-induced changes are inelastic upon decompression. Similarly, the hightemperature region 3 exhibits an increase in the density of glasses with temperature, but this increase in density is gradual compared to the mid-temperature stage. Interestingly, the aforementioned classification also agrees well with the densification behavior of a sodium borosilicate glass investigated by Østergaard et al. (2015) (Figure 2).

In 1964, Mackenzie (1964) studied the temperature dependence of permanent densification below $T_{\mathrm{g}}$, with densification being directly proportional to the applied temperature at a given pressure. This study was followed by others, investigating the influence of temperature on the densification behavior of glasses, focusing on $v-\mathrm{SiO}_{2}$ (McMillan et al., 1984) and other silicate-based glasses (Uhlmann, 1973). Uhlmann (1973) reported an increased degree of densification with increasing temperature in alkali 


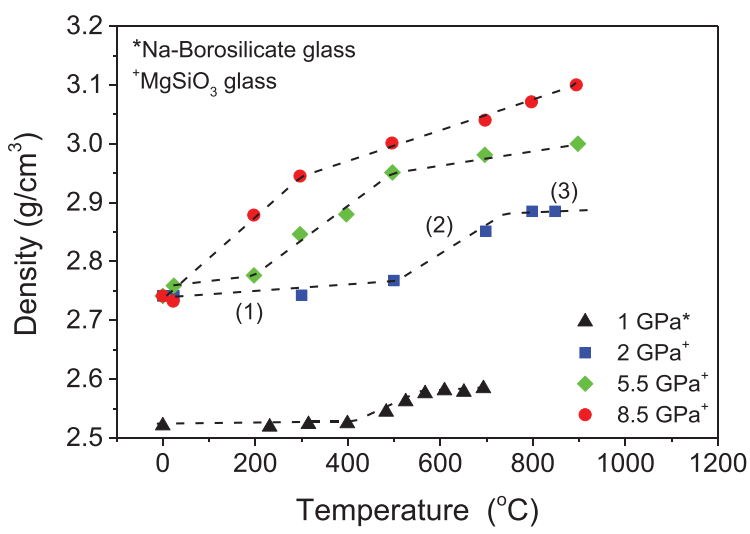

FIGURE 2 | Density of $\mathrm{MgSiO}_{3}\left(T_{\mathrm{g}}=766^{\circ} \mathrm{C}\right)$ and Na-borosilicate glasses $\left(T_{\mathrm{g}}=567^{\circ} \mathrm{C}\right)$ as a function of pressure and temperature. Dashed lines are guides for the eyes. Labeled numbers indicate the stages of the densification. Data are taken from the studies by Yamada et al. (2010) and Østergaard et al. (2015).

silicate glasses and ascribed it to the decrease of relaxation time as the temperature of the pressurization treatment approaches $T_{\mathrm{g}}$. However, permanent densification is also possible at temperatures significantly lower than $T_{\mathrm{g}}$ at which significant structural relaxation is not anticipated. Studies on pressure-induced changes in $v$ $\mathrm{SiO}_{2}$ at room temperature have shown that detectable changes can first be seen at pressures beyond $8 \mathrm{GPa}$ (Martinet et al., 2015), but application of temperature of around $0.54-0.66 T_{\mathrm{g}}\left(T_{\mathrm{g}}\right.$ in Kelvin) results in notable structural changes even at $4 \mathrm{GPa}$ (McMillan et al., 1984), with an accompanying pressure-induced increase in density between 5.8 and 6.4\% (McMillan et al., 1984; Poe et al., 2004). Modest compression of inorganic melts slightly above $T_{\mathrm{g}}$, at pressures ranging from a few hundreds of $\mathrm{MPa}$ to $\sim 1 \mathrm{GPa}$, and the generation of glasses from these melts was considered in the early 2000s (Wondraczek and Behrens, 2007; Wondraczek et al., 2007a,b; Yue et al., 2007), following-up on similar experiments that had previously been conducted on organic liquids (Atake and Angell, 1979) to introduce the fictive pressure, $p_{\mathrm{f}}$ (Gupta, 1988 ), as an addition to fictive temperature, $T_{\mathrm{f}}$, in the description of the potential energy of glasses.

Smedskjaer et al. (2014a) investigated the influence of compression temperature between $0.75 T_{\mathrm{g}}$ and $T_{\mathrm{g}}$ on permanent density changes in an aluminosilicate glass. Permanent densification at $1 \mathrm{GPa}$ was observed at $0.75 T_{\mathrm{g}}$, even though the relaxation time at this temperature is around 500 years. However, the increase in density is larger at $T_{\mathrm{g}}$, where the relaxation time is on the order of $1 \mathrm{~min}$. Hence, at higher temperatures, the kinetic processes responsible for densification increase in frequency and might to some extend be described by atomic rearrangements such as viscous flow, whereas the finding of permanent densification at lower temperatures suggests a non-viscous mechanism to be partly responsible for densification during compression (Smedskjaer et al., 2014a). The influence of temperature on pressure-induced changes in the structure of $v$ - $\mathrm{SiO}_{2}$ reveals that the MRO of the hot-compressed sample is distinct from that of the complementary cold-compressed one at room temperature (Guerette et al., 2015). Furthermore, the high-temperature compression gives rise to glasses with improved thermal and mechanical stability in comparison to the glasses compressed at low temperatures (Guerette et al., 2015). Thus, high temperature enables different structural transformations to facilitate densification, which are not possible at room temperature (Guerette et al., 2015; Martinet et al., 2015). This conclusion acknowledges previous observations that revealed a decoupling of enthalpic and volumetric effects (potential energy and density), i.e., relaxation on different structural length scales, as a result of pressurization (Wondraczek and Behrens, 2007). Besides the different structural densification mechanism, a higher temperature promotes reorganization and relaxation of structures, thus minimizing the stresses and leading to a more homogenous and stable structure compared to that obtained at lower temperatures, which is usually strained (Martinet et al., 2015). For example, Martinet et al. (2015) calculated the angular distribution angles for threefold rings in the case of $v-\mathrm{SiO}_{2}$, which were found to be $2.4 \pm 0.3^{\circ}$ for pristine glass, $2.3 \pm 0.3^{\circ}$ for hot-compressed glass, and $3.6 \pm 0.3^{\circ}$ for cold-compressed glass. This clearly shows that the threefold rings are more strained in cold-compressed glasses in comparison to those compressed even at temperatures as low as $\sim 0.93 T_{\mathrm{g}}$. Moreover, by increasing the temperature, the pressure below which the structure changes are reversible upon decompression decreases. For example, it is possible to obtain densified $v-\mathrm{SiO}_{2}$ with a density of $2.5 \mathrm{~g} \mathrm{~cm}^{-3}$ through $5 \mathrm{GPa} / 1,023 \mathrm{~K}$ or $16 \mathrm{GPa} /$ room temperature compression (Martinet et al., 2015).

\section{PRESSURE-INDUCED STRUCTURAL CHANGES}

Pressure treatment of glasses has been shown to drastically affect the macroscopic properties, such as density, viscosity, and mechanics (Yoshimoto et al., 1989; Toplis et al., 1997a; Guerette et al., 2015). The effect of pressure on these properties is influenced by how the atomic-scale structure of the glass accommodates the overall network densification. Therefore, understanding the atomic structure (e.g., coordination numbers and degree of polymerization) of glasses upon compression is essential for understanding the pressure dependence of the macroscopic properties. The pressure-induced structural changes that occur include changes in the next-nearest neighbor (NNN) distributions and ring statistics (Lee, 2010; Sonneville et al., 2013), number of non-bridging oxygen (NBO) (Xue and Stebbins, 1993; George and Stebbins, 1996), atomic coordination number of network-former cations (Smedskjaer et al., 2014b), and network-former/modifier-oxygen bond distances (Xue and Stebbins, 1993; Sonneville et al., 2013).

Based on the knowledge of pressure-induced structural changes in crystals, it is expected that pressure treatment of glasses will involve changes in the coordination number of the network formers (Sakka and Mackenzie, 1969; Lee, 2010), in addition to other changes in short- and intermediate-range order. The structure of densified glasses has been investigated using a variety of experimental and theoretical tools. Magic angle spinning (MAS) nuclear magnetic resonance (NMR) spectroscopy 
along with neutron and $\mathrm{x}$-ray diffraction studies have been some of the most powerful tools for identification and quantification of changes in the SRO in glasses (Lee, 2010; Salmon and Zeidler, 2015; Salmon et al., 2016), whereas Raman and IR spectroscopy have been successfully employed to understand the changes in the MRO (Jin et al., 1994; Inamura et al., 2001; Mantisi et al., 2010; Svenson et al., 2016b).

One of the initial studies investigating the influence of compression on structure was performed by Mackenzie (1963a) on $v-\mathrm{SiO}_{2}$ at $8 \mathrm{GPa} / 848 \mathrm{~K}$ using IR spectroscopy. An $\sim 18 \%$ increase in density of glasses was observed without any notable changes in the glass structure as probed by IR. A relatively large number of more recent experimental studies and theoretical simulations have resulted in considerable progress toward understanding the influence of compression on the glass structure (Jin et al., 1994; Wright et al., 2000; Allwardt et al., 2004, 2005a,b; Ghosh et al., 2014; Bista et al., 2015). The majority of the studies focus on pressure-quenching experiments (Allwardt et al., 2004, 2005a,b; Lee, 2010), with a small fraction on hot compression (Zhang and Soga, 1991; Wondraczek et al., 2007b, 2010; Wu et al., 2009; Smedskjaer et al., 2014a,b; Bechgaard et al., 2016), but the types of changes in the two related densification methods are in general qualitatively identical. In general, compression at elevated temperature leads to an increase in coordination number of the network-forming cations. However, the extent of this change depends on glass composition, where the concentration of NBOs is identified as the key parameter (Allwardt et al., 2004; Du et al., 2004; Lee et al., 2004; Chen et al., 2011). That is, it has been suggested that in glasses with significant number of NBOs, the application of pressure results in the formation of higher coordinated cation with the displacement of following equilibrium to the right (Du et al., 2004),

$$
\mathrm{NBO}+\mathrm{TO}_{n} \Rightarrow \mathrm{TO}_{n+1}
$$

where $T$ is the network cation initially in trigonal or tetrahedral coordination and the subscript indicates the number of coordinating oxygens. However, it is also important to note that changes in boron and aluminum coordination are observed to increase even in the case of $\mathrm{NaAlSi}_{3} \mathrm{O}_{8}$ (Allwardt et al., 2005a; Gaudio et al., 2015) and boron oxide glasses or melts (Brazhkin et al., 2010), where little or no NBOs are present (although the extent of coordination change is small compared to NBO-rich systems). Moreover, NBO-free crystalline phases of $\mathrm{SiO}_{2}$ and $\mathrm{B}_{2} \mathrm{O}_{3}$ transform to polymorphs with higher cation and anion coordination, suggesting that different mechanisms could play a role in generation of higher coordinated aluminum and boron in some compositional and pressure ranges. One of the alternative mechanisms involves the formation of NBOs through oxygen triclusterrs, which are oxygen bonded to three instead of two tetrahedrally coordinated network formers (Toplis et al., 1997b; Allwardt et al., 2005a; Jaworski et al., 2016).

\section{Boron Speciation}

Boric oxide $\left(\mathrm{B}_{2} \mathrm{O}_{3}\right)$ is widely used as a network-forming constituent in many high-tech glass materials owing to its contribution to high glass-forming ability and low melting temperature and for its favorable impact on thermal, mechanical, and optical properties
(Bray, 1985; Youngman et al., 1995). The basic building unit of $v$ $\mathrm{B}_{2} \mathrm{O}_{3}$ is $\mathrm{BO}_{3}$ units, which are joined to form boroxol rings (Shelby, 2005). The initial introduction of oxygen from a modifier oxide to $v-\mathrm{B}_{2} \mathrm{O}_{3}$ causes boron to change its coordination from $\mathrm{B}^{\mathrm{III}}$ to $\mathrm{B}^{\mathrm{IV}}$ with no NBO formation, while further addition of oxygen leads to the formation of NBOs. The structure of borate and borosilicate glasses at both ambient and high-pressure conditions has been relatively well studied and reviewed (Lee, 2010). However, the permanent pressure-induced structural changes near $T_{\mathrm{g}}$ have only recently been revealed using diverse experimental tools (Wondraczek et al., 2007b; Wu et al., 2009; Smedskjaer et al., $2014 a, b)$. The general mechanism for the densification of $\mathrm{B}_{2} \mathrm{O}_{3}$ based glasses involves changes in both SRO and MRO (Lee et al., 2005b).

The first study on the influence of hot compression on borate glass structure dates back to 1963 when Mackenzie (1963a) investigated the densification of $\mathrm{B}_{2} \mathrm{O}_{3}$ glasses in the rigid state. In 1988, Chason and Spaepen (1988) reported the pressureinduced structural changes in $v-\mathrm{B}_{2} \mathrm{O}_{3}$ compressed at $1-1.5 \mathrm{GPa}$ at $573 \mathrm{~K}$ for $30 \mathrm{~min}$, resulting in $\sim 10 \%$ densification. Based on $\mathrm{X}$-ray diffraction analyses, this densification was attributed to the change in $\mathrm{B}-\mathrm{O}-\mathrm{B}$ bond angles and rotation around the $\mathrm{B}-\mathrm{O}$ bonds joining them. A structural model consisting of $\mathrm{BO}_{3}$ triangles forming a plain ribbon-like structure was proposed, suggesting that densification occurs as a result of buckling of these ribbonlike structures. In addition, pressure quenched (Brazhkin et al., 2010) and cold-compressed (Lee et al., 2005a) $\mathrm{B}_{2} \mathrm{O}_{3}$ glasses have been studied using ${ }^{11} \mathrm{~B}$ MAS NMR and inelastic X-ray scattering, respectively, presenting clear evidence of absence of coordination change at low pressures ( $<4 \mathrm{GPa}$ ). However, Lee et al. (2005b) have reported the presence of higher fractions of boron in fourfold coordination in pressure quenched glasses. The origin of this discrepancy has been attributed to the presence of an impurity of a high-pressure crystalline phase and/or presence of water as an impurity in the investigated glasses (Brazhkin et al., 2010).

Hot compression of modified borate and borosilicate glasses typically results in an increase of the boron coordination number (Wondraczek et al., 2007b). For example, Figure 3 shows an increase in the amount of fourfold boron $\left(\mathrm{B}^{\mathrm{IV}}\right)$ units upon 0.1-0.5 GPa compression at $983 \pm 5 \mathrm{~K}$ of a commercial aluminoborosilicate glass (Wu et al., 2009). The ${ }^{11} \mathrm{~B}$ MAS NMR spectra clearly show that the fraction of tetrahedral to total boron $\left(N_{4}\right)$ increases from 0.23 to 0.29 with increasing pressure (Wu et al., 2009). Interestingly, the change in coordination number is observed at much lower pressures $(0.1 \mathrm{GPa})$ compared to that in the pure $\mathrm{B}_{2} \mathrm{O}_{3}$ glasses discussed earlier. This behavior is presumably due to the presence of NBOs in the modified glasses, which facilitate the structural transformation at much lower temperature and pressure as discussed earlier. On the contrary, an earlier study using IR and Raman spectroscopy (Zhang and Soga, 1991) investigated a series of hot-compressed alkali borate glasses revealing the pressure-induced partial conversion of tetraborate to boroxol rings plus NBOs in low-alkali glasses and to diborate groups in higher alkali glasses. Furthermore, Svenson et al. (2014a) observed an increase in the amount of $\mathrm{B}^{\mathrm{IV}}$ units from 70 to 77 at.\% upon $1 \mathrm{GPa}$ compression at $T_{\mathrm{g}}$ of sodium borosilicate glass. Recently, the nature of transition state for $\mathrm{BO}_{3}$ to $\mathrm{BO}_{4}$ 


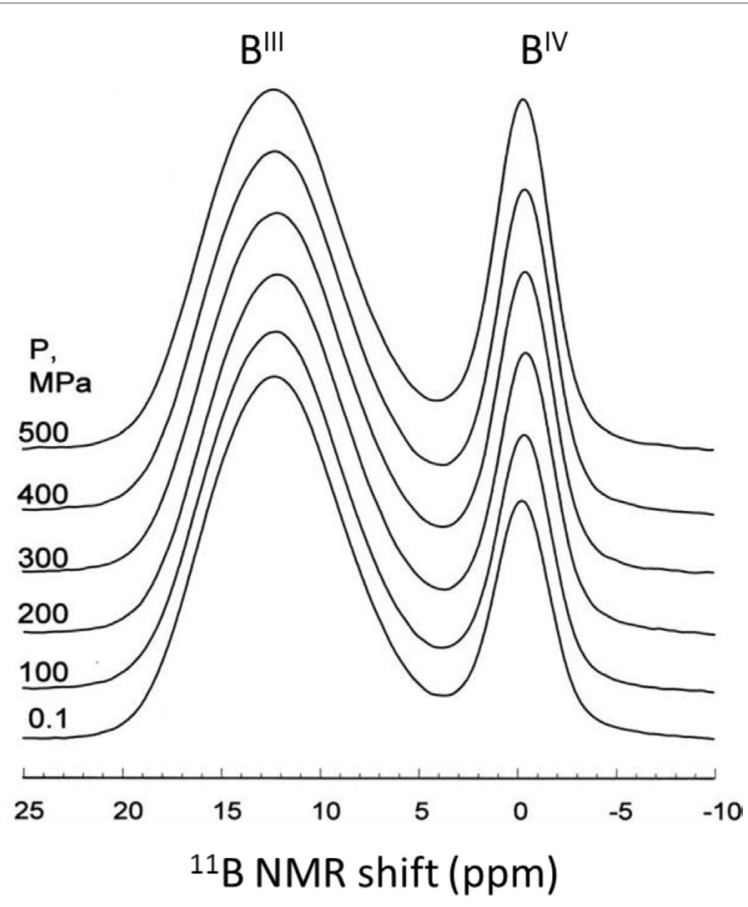

FIGURE $3 \mid{ }^{11} \mathrm{~B}$ magic angle spinning nuclear magnetic resonance spectra for isostatically compressed E-glass samples (14.1 T), normalized to height of $\mathbf{B}^{\text {III }}$ peak. Adapted from the study by Wu et al. (2009), with the permission of AIP Publishing.

conversion has been investigated in situ at high pressure using ${ }^{11} \mathrm{~B}$ MAS NMR spectroscopy, reporting that an elastic out-of-plane displacement of $\mathrm{B}$ atom in the $\mathrm{BO}_{3}$ units serves as a transition state for the for $\mathrm{BO}_{3}-\mathrm{BO}_{4}$ transformation (Edwards et al., 2014). Furthermore, the pressure-induced change in boron coordination has been found to be higher for the hot-compressed glasses at $T_{\mathrm{g}}$ in comparison to the pressure quenched glasses. Bista et al. (2015) recently demonstrated that the transient pressure drops during the pressure quenching lead to a significant reduction in the recovered structural changes in glasses, i.e., pressure experiments performed near $T_{\mathrm{g}}$ minimize these losses in structural changes.

In another study by Bista et al. (2016), it was shown that the field strength of the modifier cations influences the pressureinduced $\mathrm{B}^{\mathrm{III}}$-to- $\mathrm{B}^{\mathrm{IV}}$ transformation. That is, higher field strength cation promotes $\mathrm{B}^{\mathrm{III}}$-to- $\mathrm{B}^{\mathrm{IV}}$ transformation by stabilizing the bonding between newly formed $\mathrm{B}^{\mathrm{IV}}$ and neighboring network cations such as $\mathrm{Al}$ and $\mathrm{Si}$ (Morin et al., 2014). In addition to the dependence of boron coordination on the applied pressure, the fraction of $\mathrm{B}^{\mathrm{IV}}$ increases with an increase in the compression temperature and duration of the sub- $T_{\mathrm{g}}$ compression (Østergaard et al., 2015). However, the change in coordination attains a saturation value with no further change upon further increase in compression temperature and time (Østergaard et al., 2015). Figure 4A shows the quantitative evolution of $N_{4}$ in a sodium borosilicate glass with increasing compression temperature and duration. While the NMR spectra (Figure 4B)

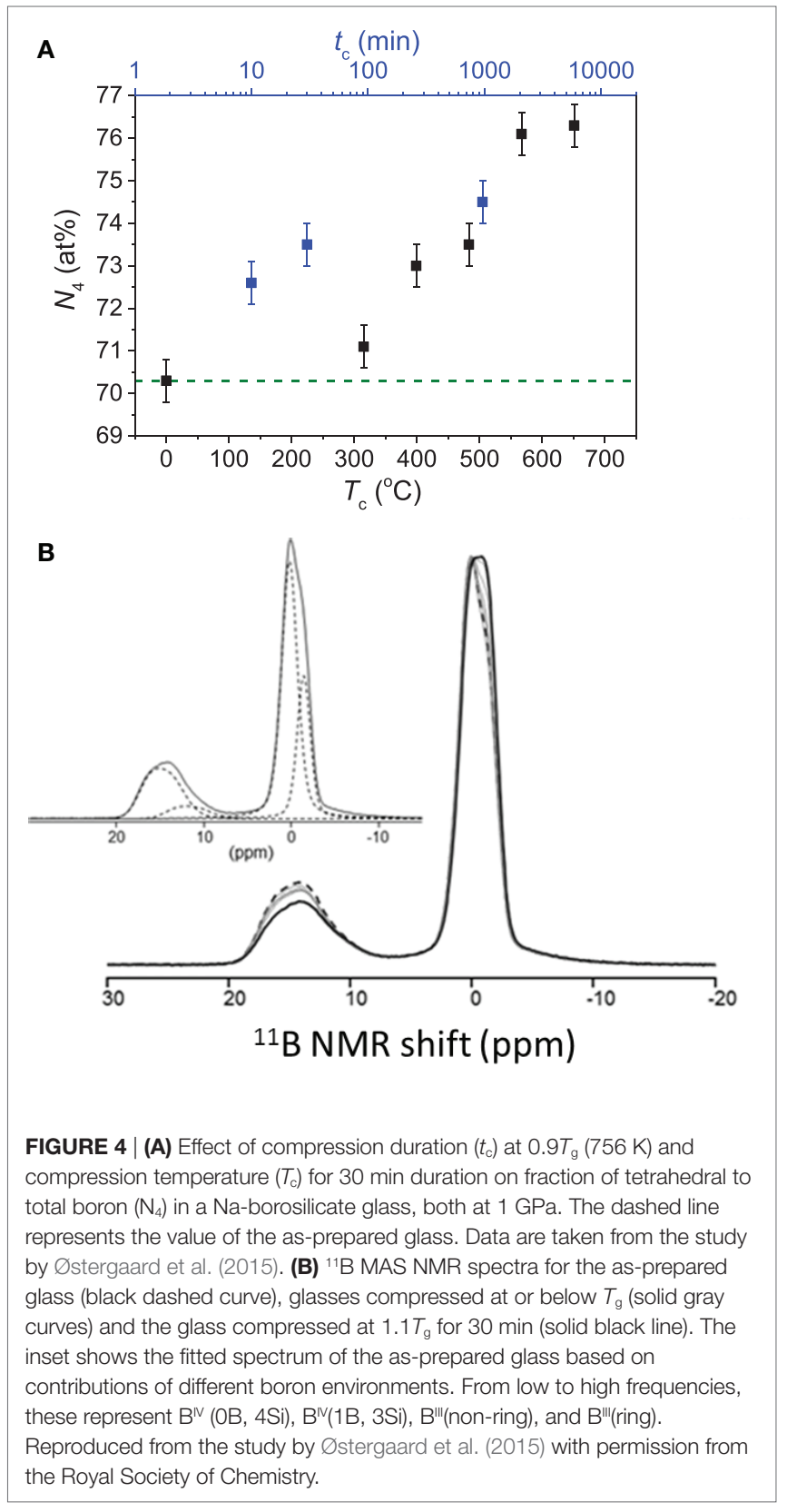

clearly show boron in threefold and fourfold coordinations, there are two resolved $\mathrm{B}^{\mathrm{IV}}$ sites in the boron structure in the glasses due to variation in NNN. Thus, compression also induces an increased shielding by increasing the contribution B-O-Si linkages and a simultaneous decrease in fraction of $\mathrm{B}-\mathrm{O}-\mathrm{B}$ linkages (Østergaard et al., 2015). This was also found in earlier work on pressure quenched borosilicate glasses by Du et al. (2004), who reported pressure-induced network ordering, attributed to decrease in fraction of the energetically unfavorable $\mathrm{B}^{\mathrm{IV}}-\mathrm{O}-\mathrm{B}^{\mathrm{IV}}$ linkages upon conversion from $\mathrm{B}^{\mathrm{III}}$ to $\mathrm{B}^{\mathrm{IV}}$ (Abe, 1952; Wang and Stebbins, 1999). Moreover, compression results in an increase in the fraction of $\mathrm{B}^{\mathrm{III}}$ in non-ring sites with increasing compression temperature (Østergaard et al., 2015). These results are 
comparable to the results obtained for cold-compressed (Wright et al., 2000) and pressure quenched vitreous $\mathrm{B}_{2} \mathrm{O}_{3}$ (Lee et al., 2005a; Brazhkin et al., 2010), i.e., the breakdown of boroxol rings upon compression.

\section{Aluminum Speciation}

In Al-containing glasses prepared at ambient conditions, the structural configuration of aluminum depends on the relative concentrations of the network modifiers and network formers present in the system. For example, in the case of aluminosilicate and boroaluminosilicate glasses, most of the $\mathrm{Al}^{3+}$ ions are found in tetrahedral configuration when the molar percentage of modifier is higher than that of $\mathrm{Al}_{2} \mathrm{O}_{3}$, i.e., $\left[\mathrm{Al}_{2} \mathrm{O}_{3}\right]$ / $\left(\left[\mathrm{M}_{2} \mathrm{O}\right]+[\mathrm{MO}]\right)<1$, and in fivefold or sixfold coordination when the molar percentage of modifier is less than that of $\mathrm{Al}_{2} \mathrm{O}_{3}$, i.e., $\left[\mathrm{Al}_{2} \mathrm{O}_{3}\right] /\left(\left[\mathrm{M}_{2} \mathrm{O}\right]+[\mathrm{MO}]\right)>1$. However, not all the $\mathrm{Al}$-containing glasses behave accordingly, and there have been several studies showing non-zero $\mathrm{Al}^{\mathrm{V}}$ and $\mathrm{Al}^{\mathrm{VI}}$ concentrations in highly peralkaline aluminosilicate and aluminoborate glasses (Malfait et al., 2012; Bechgaard et al., 2016; Januchta et al., 2017). Furthermore, the behavior of aluminum is different when phosphate is present as network-forming species, with octahedral species dominating at low alumina content and tetrahedral species at high alumina content (Wüllen et al., 2007). For example, significant amounts of $\mathrm{Al}^{\mathrm{V}}$ and $\mathrm{Al}^{\mathrm{VI}}$ were observed in a series of $\mathrm{Al}_{2} \mathrm{O}_{3}-\mathrm{Na}_{2} \mathrm{O}-\mathrm{P}_{2} \mathrm{O}_{5}$ glasses when $\left[\mathrm{P}_{2} \mathrm{O}_{5}\right]>\left[\mathrm{Al}_{2} \mathrm{O}_{3}\right]=\left[\mathrm{Na}_{2} \mathrm{O}\right]$, while $\mathrm{Al}^{\mathrm{IV}}$ was the predominant species when $\left[\mathrm{P}_{2} \mathrm{O}_{5}\right]>\left[\mathrm{Al}_{2} \mathrm{O}_{3}\right]>\left[\mathrm{Na}_{2} \mathrm{O}\right]$ (Zhang et al., 2005).

${ }^{27} \mathrm{Al}$ MAS and triple quantum (3Q) MAS NMR spectroscopy have been widely applied to understand the influence of compression on the $\mathrm{Al}$ coordination environment in oxide glasses. The initial efforts to unravel the influence of pressure on Al coordination were carried out on pressure quenched $\mathrm{NaAlO}_{2}-\mathrm{SiO}_{2}$ glasses due to their good glass-forming ability and relatively low melting point compared to other aluminosilicates (Kushiro, 1976, 1978; Sharma et al., 1979; McMillan and Graham, 1980; Mysen et al., 1980; Hochella and Brown, 1985). By using IR and X-ray spectroscopy, Velde and Kushiro (1978) reported a change in the $\mathrm{Al}$ coordination from fourfold to sixfold in $\mathrm{Na}_{2} \mathrm{O}-\mathrm{Al}_{2} \mathrm{O}_{3}-\mathrm{SiO}_{2}$ glasses upon pressure quenching the melts from $3 \mathrm{GPa}$. However, further investigations using Raman and $\mathrm{x}$-ray spectroscopy found no evidence to support this increasing $\mathrm{Al}$ coordination in glass-forming melts quenched from pressures up to $4 \mathrm{GPa}$ (Sharma et al., 1979; McMillan and Graham, 1980; Mysen et al., 1980; Hochella and Brown, 1985).

More recent investigations on the pressure-induced changes in Al coordination in partially depolymerized glasses show a change in $\mathrm{Al}$ coordination upon compression at elevated temperatures at pressures as low as $100 \mathrm{MPa}$ (Allwardt et al., 2003, 2004, 2005a,b; Wu et al., 2009; Smedskjaer et al., 2014a; Bechgaard et al., 2016). For example, Figure 5A shows NMR spectra of aluminoborosilicate glasses with NBOs compressed at 1.5 and $3 \mathrm{GPa}$ near $T_{\mathrm{g}}$ (Bista et al., 2016). These spectra show well-resolved multiple coordination environments. $\mathrm{Al}^{\mathrm{V}}$ and $\mathrm{Al}^{\mathrm{VI}}$ are the predominant species at 1.5 and $3 \mathrm{GPa}$, whereas at $1 \mathrm{~atm}, \mathrm{Al}^{\mathrm{IV}}$ is the predominant $\mathrm{Al}$ species in the glasses (Bista et al., 2016). This effect of pressure on $\mathrm{Al}$ coordination has also been found in related studies using
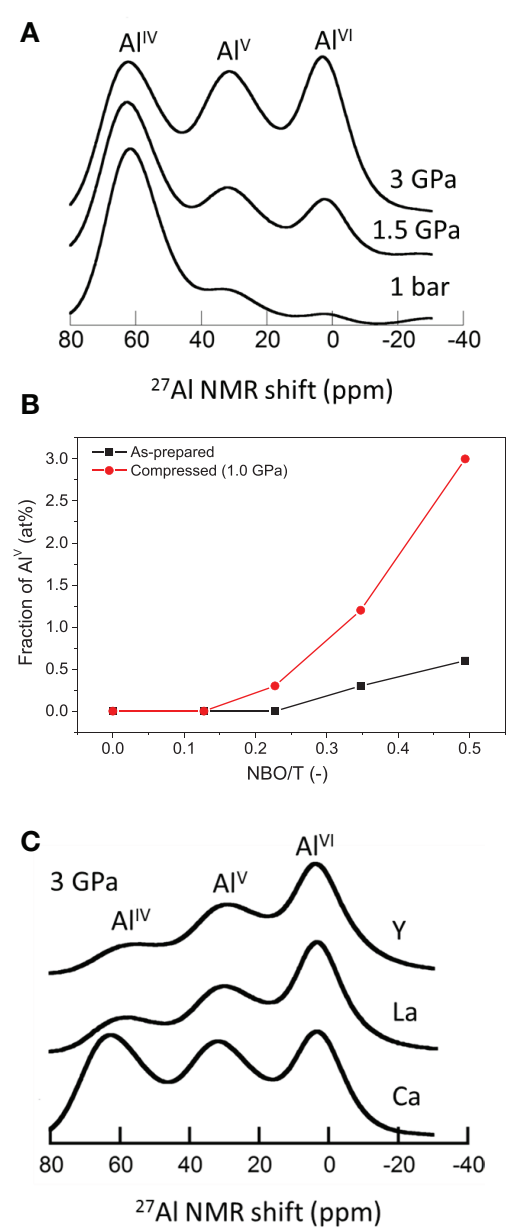

FIGURE 5 | (A) ${ }^{27} \mathrm{Al}$ MAS NMR (18.8 T) spectra of Ca-aluminoborosilicate glasses recovered from 1 bar, $1.5 \mathrm{GPa}$, and $3 \mathrm{GPa}$. Adapted from the study by Bista et al. (2015) with the permission of AIP Publishing. (B) Fraction of fivefold coordinated aluminum (AlY) as a function of the calculated number of non-bridging oxygens per tetrahedrally coordinated cation NBO/T for as-prepared and compressed (at 1.0 GPa) Na-aluminosilicate glasses. Reprinted from the study by Bechgaard et al. (2016), with permission from Elsevier. (C) Pressure dependence of average aluminum coordination for $\mathrm{Ca}$, $\mathrm{La}$, and $\mathrm{Y}$ containing aluminoborosilicate glasses. Adapted from the study by Bista et al. (2015), with the permission of AIP Publishing.

extended $\mathrm{x}$-ray absorption fine structure, IR, ${ }^{27} \mathrm{Al}$ MAS-NMR, and Raman spectroscopies (Li et al., 1995; Yarger et al., 1995; Allwardt et al., 2003, 2004, 2005a,b, 2007; Kelsey et al., 2009; Wu et al., 2009; Bista et al., 2015, 2016; Bechgaard et al., 2016). The increase in coordination number is a way for the glasses to accommodate increasing densification under the applied pressure. Based on studies of pressure quenched aluminosilicate glasses, a mechanism for the formation of high-coordinated $\mathrm{Al}$ species in non-charge balanced glasses/melts has been proposed (Lee et al., 2004; Kelsey et al., 2009; Chen et al., 2011):

$$
\begin{aligned}
& \mathrm{Si}-\mathrm{NBO}+4^{[4]} \mathrm{Si}-\mathrm{O}-{ }^{[4]} \mathrm{Al} \rightarrow 5^{[4]} \mathrm{Si}-\mathrm{O}-{ }^{[5]} \mathrm{Al} . \\
& 2 \mathrm{Si}-\mathrm{NBO}+4^{[4]} \mathrm{Si}-\mathrm{O}-{ }^{[4]} \mathrm{Al} \rightarrow 6^{[4]} \mathrm{Si}-\mathrm{O}-{ }^{[6]} \mathrm{Al} .
\end{aligned}
$$


High-coordinated Al species are generated when sufficient NBOs are present in ambient pressure glasses. Thus, the NBOs present in the glass network are consumed by $\mathrm{Al}$ for charge compensation, and this leads to reduction in the number of NBOs in glasses. Figure 5B shows the variation in the fraction of $\mathrm{Al}^{\mathrm{V}}$ as a function of $\mathrm{NBO}$ per tetrahedra $(\mathrm{NBO} / \mathrm{T})$ obtained from quantification of ${ }^{27} \mathrm{Al}$ MAS NMR spectra of Na-aluminosilicate glasses hot compressed at $1 \mathrm{GPa}$ (Bechgaard et al., 2016). The average $\mathrm{Al}$ coordination number is higher in glasses with a higher fraction of NBO/T. Moreover, glasses with a higher amount of NBOs at ambient condition undergo a more pronounced change in $\mathrm{Al}$ coordination upon hot compression. These results imply that the degree of polymerization at ambient conditions plays an important factor in controlling the response of $\mathrm{Al}$ coordination to pressure (Yarger et al., 1995; Lee, 2004).

In addition to the content of $\mathrm{NBO}$, the pressure-induced changes in $\mathrm{Al}$ coordination are also strongly influenced by the field strength of the modifying cations, which is also valid for glasses prepared at ambient conditions (Morin et al., 2014). As shown in Figure 5C, for the glasses recovered from $3 \mathrm{GPa}$, a higher concentration of $\mathrm{Al}^{\mathrm{V}}$ and $\mathrm{Al}^{\mathrm{VI}}$ are observed in glasses containing higher field strength modifier cations, and the increase in Al coordination with pressure is more rapid in glasses with cation with higher field strength. A similar effect of cation field strength has been observed in previous studies on pressure quenched Al-containing glasses (Kelsey et al., 2009; Wu and Stebbins, 2009). This is likely because the higher field strength cations outcompete the $\mathrm{Al}^{3+}$ ions for the available nearby oxygen atoms, thus forcing $\mathrm{Al}^{3+}$ to bond with a greater number of oxygens with longer bonds, therefore increasing its coordination (Bista et al., 2016).

Similar to the behavior of boron, the average Al coordination number is higher in glasses recovered from hot compression compared to glasses quenched from above the liquidus temperature. Gaudio et al. (2015) investigated albite glasses and melts at pressure up to $7 \mathrm{GPa}$ and reported a significantly higher $\mathrm{Al}$ coordination in hot-compressed glasses than glasses quenched from super liquidus temperatures. Similarly, a recent study of $\mathrm{Na}$ - and Ca-aluminosilicate glasses and melts at 2 and $3 \mathrm{GPa}$, respectively, reported considerably higher $\mathrm{Al}$ coordination in glasses annealed near $T_{\mathrm{g}}$ than those quenched from melts, such that two Na-aluminosilicate glasses exhibited similar Al speciation when quenched from $783 \mathrm{~K}$ at $1.5 \mathrm{GPa}$ and $1473 \mathrm{~K}$ at $2 \mathrm{GPa}$ (Bista et al., 2015). However, an earlier study on Na-aluminosilicate glasses compressed at $10 \mathrm{GPa}$ has shown a contradictory behavior, i.e., glasses quenched from melts exhibit a higher amount of highcoordinated $\mathrm{Al}$ species than glasses pressurized neat $T_{\mathrm{g}}$, but it has been attributed to incomplete structural relaxation of these glasses upon compression (Allwardt et al., 2005a).

\section{Silicon Speciation}

The basic building unit of silicate glasses is the $\mathrm{SiO}_{4}$ tetrahedron, which can be connected to neighboring $\mathrm{SiO}_{4}$ tetrahedra via $\mathrm{Si}-\mathrm{O}-\mathrm{Si}$ bonds. Each oxygen atom is shared between two silicon atoms, which occupy the centers of linked tetrahedra. These tetrahedra are commonly referred to as $Q^{n}(n=1,2,3,4)$ units, where $n$ describes the number of bridging oxygens connected to the tetrahedron (Mysen, 1988). Even for integer average values of $n$, multiple $Q$-species have been shown to exist. For instance, if $n=3, Q^{3}$ will not be the only $Q$-species present in the structure, as there will also be $Q^{4}$ and $Q^{2}$ species present (Brawer and White, 1975, 1977; Murdoch et al., 1985; Brandriss and Stebbins, 1988; Zhang et al., 1997).

Vitreous $\mathrm{SiO}_{2}$ and related $\mathrm{SiO}_{2}$-based glasses have been the object in numerous high-pressure studies in the literature (Mackenzie, 1963a; McMillan et al., 1984; Guerette et al., 2015). The majority of the initial work focused on understanding the influence of pressure on the structure of $v-\mathrm{SiO}_{2}$ (Mackenzie, 1963a; McMillan et al., 1984). Network densification in silica or silicate-based glasses is typically accommodated through changes in bond angle distribution, ring statistics, and silicon coordination number (McMillan et al., 1984; Sato et al., 2011). These pressure-induced structural changes have been investigated by various techniques such as Raman, MAS NMR, neutron diffraction, and MD simulations (McMillan et al., 1984; Poe et al., 2004; Gaudio et al., 2008; Martinet et al., 2015). At room temperature, densification occurs through a process involving alteration of bond angles and the dihedral angle of glass network (Kato et al., 2011), whereas breakage and subsequent reformation of bonds (e.g., Si-O) is an important structural control of viscous flow and densification at temperatures at and above $T_{\mathrm{g}}$ (Naji et al., 2015).

Bridgman and Šimon (1953) investigated the densification of silica glass upon compression at room temperature, but the initial studies on $v-\mathrm{SiO}_{2}$ compressed at room temperature reported no significant changes in the Si coordination number. However, considering a significant broadening and weakening of the IR absorption bands, Cohen and Roy (1965) attributed densification of $\mathrm{SiO}_{2}$ to the increase of bond angle distributions, occurring as a result of the pressure-induced random packing of tetrahedral units. Later, McMillan et al. (1984) used Raman spectroscopy to investigate $v-\mathrm{SiO}_{2}$ densified at $3.95 \mathrm{GPa}$ and $\sim 0.54 T_{\mathrm{g}}$ and highlighted that the structure of $\mathrm{SiO}_{2}$ compressed at elevated temperature is similar to that of compressed at room temperature at much higher pressure. Furthermore, they reported a pressure-induced decrease in the average bond angle and buckling of fourfold siloxane rings, resulting in a decrease in the average ring size. On the contrary, Poe et al. (2004) observed no substantial changes in ring statistics for $v-\mathrm{SiO}_{2}$ compressed up to $8 \mathrm{GPa}$ at $\sim 0.66 T_{\mathrm{g}}$, attributing it to the relatively low compression temperature at which $\mathrm{Si}-\mathrm{O}$ bondbreaking and bond-making would be unlikely. They thus concluded that at such elevated temperatures and pressures, which are insufficient to affect the $\mathrm{Si}$ coordination and $\mathrm{Si}-\mathrm{O}$ bonding, the most favorable mechanism for densification is the change in the bond angle distribution and $\mathrm{Si}-\mathrm{O}$ bond length without any change in ring statistics. Furthermore, Inamura et al. (2001) investigated the structural response of $v-\mathrm{SiO}_{2}$ compressed up to $7.4 \mathrm{GPa}$ at $\sim 0.66 T_{\mathrm{g}}$, revealing changes in the MRO caused by deformation of sixfold ring structure manifested by the changes in the structural factor $S(q)$. Similar changes in the MRO have been observed is a recent study by Guerette et al. (2015) for $v-\mathrm{SiO}_{2}$ compressed up to $8 \mathrm{GPa}$ at $\sim 0.93 T_{\mathrm{g}}$. Figure 6 shows the total X-ray structure factor $S(q)$ of recovered hot-compressed $v-\mathrm{SiO}_{2}$ samples. The position of first sharp diffraction peak is related to the intermediate-range order of silica and shifts toward higher $q$ values with increase in pressure, clearly demonstrating that pressurization affects the 


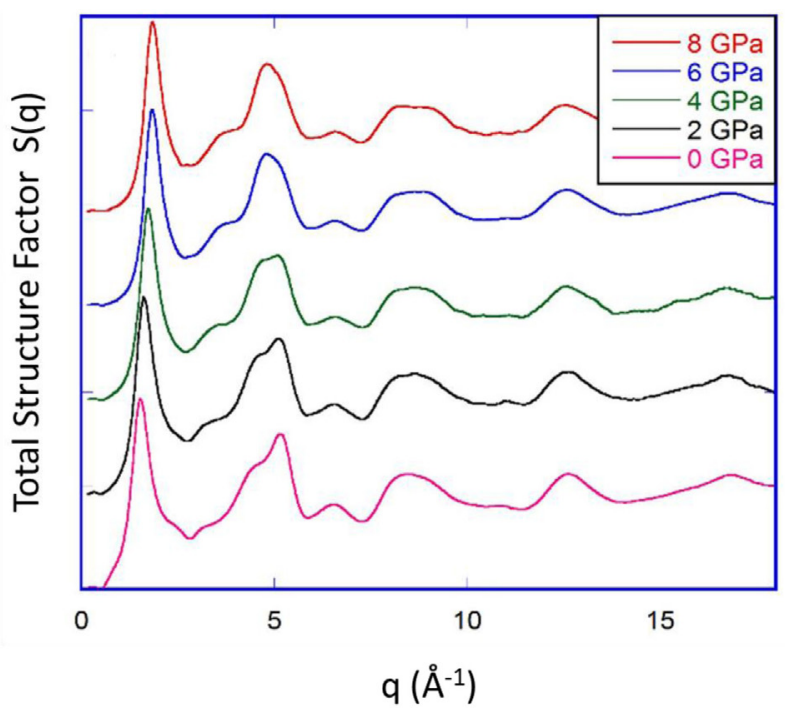

FIGURE 6 | Total X-ray structure factor $S(q)$ of silica glass hotcompressed under $2,4,6$, and $8 \mathrm{GPa}$ at $1373 \mathrm{~K}$, compared to that of pristine silica glass. Reproduced from the study by Guerette et al. (2015), with the permission of Nature Publishing group under CC-BY license (https:// creativecommons.org/licenses/by/4.0/).

MRO of $v-\mathrm{SiO}_{2}$. Several experimental and simulation studies have concluded similar results, i.e., densification in $v-\mathrm{SiO}_{2}$ is achieved by a reduction in ring size and collapse of void space (Devine and Arndt, 1987; Jin et al., 1994; Inamura et al., 2001; Trachenko and Dove, 2002, 2003).

Several MD simulation studies have also been performed to understand the pressure-induced change of ring statistics in $v$ - $\mathrm{SiO}_{2}$ (Dávila et al., 2003; Huang and Kieffer, 2004). Some MD simulation studies show that pressurization causes an increase in number of larger rings at the expense of smaller rings (Huang and Kieffer, 2004), whereas a relative decrease in fraction of fivefold and sixfold rings and increase in fraction of threefold and fourfold rings along with an increase in number of larger rings (greater than sevenfold rings) upon compression has been reported by Dávila et al. (2003). In line with the simulation results of Huang and Kieffer (2004), compression of the $v-\mathrm{SiO}_{2}$ at $5 \mathrm{GPa}$ and $\sim 0.93 T_{\mathrm{g}}$ (Martinet et al., 2015) has been found to result in no change in concentration of threefold rings, which was attributed to the temperature-induced reorganization during pressurization, resulting in the formation of large rings at the expense of smaller ones. This formation of large rings is enhanced at higher pressures, whereas the ring size distribution is not affected, i.e., possibly some smaller rings are formed simultaneously. Moreover, compression of $v-\mathrm{SiO}_{2}$ at elevated temperatures results in a more homogenous $\mathrm{MRO}$ as a result of the elimination of pores or empty spaces (Guerette et al., 2015).

Stebbins and Mcmillan (1989) and Xue et al. (1989) have revealed the formation of pressure-induced fivefold and sixfold coordinated silicon in alkali silicate glasses quenched from highpressure melts. Later, in a comparative study of $\mathrm{Na}_{2} \mathrm{Si}_{2} \mathrm{O}_{5}$ glass, Farber and Williams (1996) found major differences between the
Raman spectra of two $\mathrm{Na}_{2} \mathrm{Si}_{2} \mathrm{O}_{5}$ glasses compressed via different routes, with the structure of a hot-compressed glass at $8 \mathrm{GPa}$ and $\sim 1.1 T_{\mathrm{g}}$ being equivalent to that of a cold-compressed glass at $11 \mathrm{GPa}$. The Raman spectra indicate the formation of highcoordinated Si species as a result of both compression methods, but the $Q^{4}$ species disappear at lower pressure in glasses compressed at elevated temperature (Farber and Williams, 1996). The mechanism responsible for the formation of fivefold and sixfold coordinated Si has been investigated in pressure quenched glasses by Allwardt et al. (2004). Higher Si coordination number is preferred when NBOs are present in ambient pressure glasses, i.e., similar to the case of aluminum and boron. The reaction can be written as:

$$
\begin{gathered}
\mathrm{NBO}+4 \mathrm{BO} \rightarrow 5 \mathrm{Si}^{\mathrm{IV}}-\mathrm{O}-\mathrm{Si}^{\mathrm{V}} . \\
2 \mathrm{NBO}+4 \mathrm{BO} \rightarrow 6 \mathrm{Si}^{\mathrm{IV}}-\mathrm{O}-\mathrm{Si}^{\mathrm{VI}} .
\end{gathered}
$$

Furthermore, the formation of higher coordinated silicon is also influenced by the rate of decompression of glasses compressed at elevated temperature (Gaudio et al., 2008). Gaudio et al. (2008) have reported the formation of $\mathrm{Si}^{\mathrm{V}}$ and $\mathrm{Si}^{\mathrm{VI}}$ in the glasses recovered from $\sim 0.74 T_{\mathrm{g}}$ at $10 \mathrm{GPa}$, showing that rapidly quenched glasses exhibit a higher proportion of high-coordinated silicon than more slowly decompressed glasses, which exhibit no spectral evidence of $\mathrm{Si}^{\mathrm{V}}$. In contrast, in pressure quenched $\mathrm{K}_{2} \mathrm{Si}_{4} \mathrm{O}_{9}$ glass, $\mathrm{Si}^{\mathrm{V}}$ concentration increases at the expense of $\mathrm{Si}^{\mathrm{VI}}$ during slow decompression (Allwardt et al., 2004). This behavior has been attributed to the higher degree of polymerization exhibited by the $\mathrm{K}_{2} \mathrm{Si}_{4} \mathrm{O}_{9}$ glass, stabilizing the $\mathrm{Si}^{\mathrm{V}}$ species.

The presence of aluminum in silicate glasses complicates understanding of the response of these glasses to densification as both $\mathrm{Al}$ and $\mathrm{Si}$ can increase their coordination number. Studies of compression on crystalline materials suggest that higher coordinated $\mathrm{Al}$ is formed at much lower pressure compared to $\mathrm{Si}$ (Waff, 1975). This has been confirmed by recent MAS NMR studies in boroaluminosilicate glasses (Wu et al., 2009), showing that the presence of NBOs facilitates the coordination change in boron or aluminum ahead of silicon, where ${ }^{29} \mathrm{Si}$ MAS NMR spectra show a slight shift in the peak position attributed to a change in $\mathrm{Si}-\mathrm{O}-\mathrm{Si}$ bond angle (Wu et al., 2009).

\section{Network Modifiers}

In addition to pressure-induced changes in the SRO and MRO of network formers, compression can also influence the modifieroxygen bond length and bond angle, but only studies on $\mathrm{Na}$ have been reported to our knowledge. This is presumably because ${ }^{23} \mathrm{Na}$ MAS NMR is an effective probe for studying the Na-O distance distribution on the basis of known correspondence between $\mathrm{Na}-\mathrm{O}$ bond distance and ${ }^{23} \mathrm{Na}$ chemical shift. Figure 7 shows the ${ }^{23} \mathrm{Na}$ MAS NMR spectra for Na-borosilicate at $1 \mathrm{~atm}$ and recovered from hot compression at $1 \mathrm{GPa}$ (Svenson et al., 2014a), revealing a distinct change in $\mathrm{Na}$ environment upon compression. Such peak shifts to a higher frequency with pressure are found in fully polymerized and partially polymerized borosilicate and aluminosilicate glasses (Østergaard et al., 2015; Svenson et al., 2016c). In addition, 3Q MAS NMR has been conducted on the 


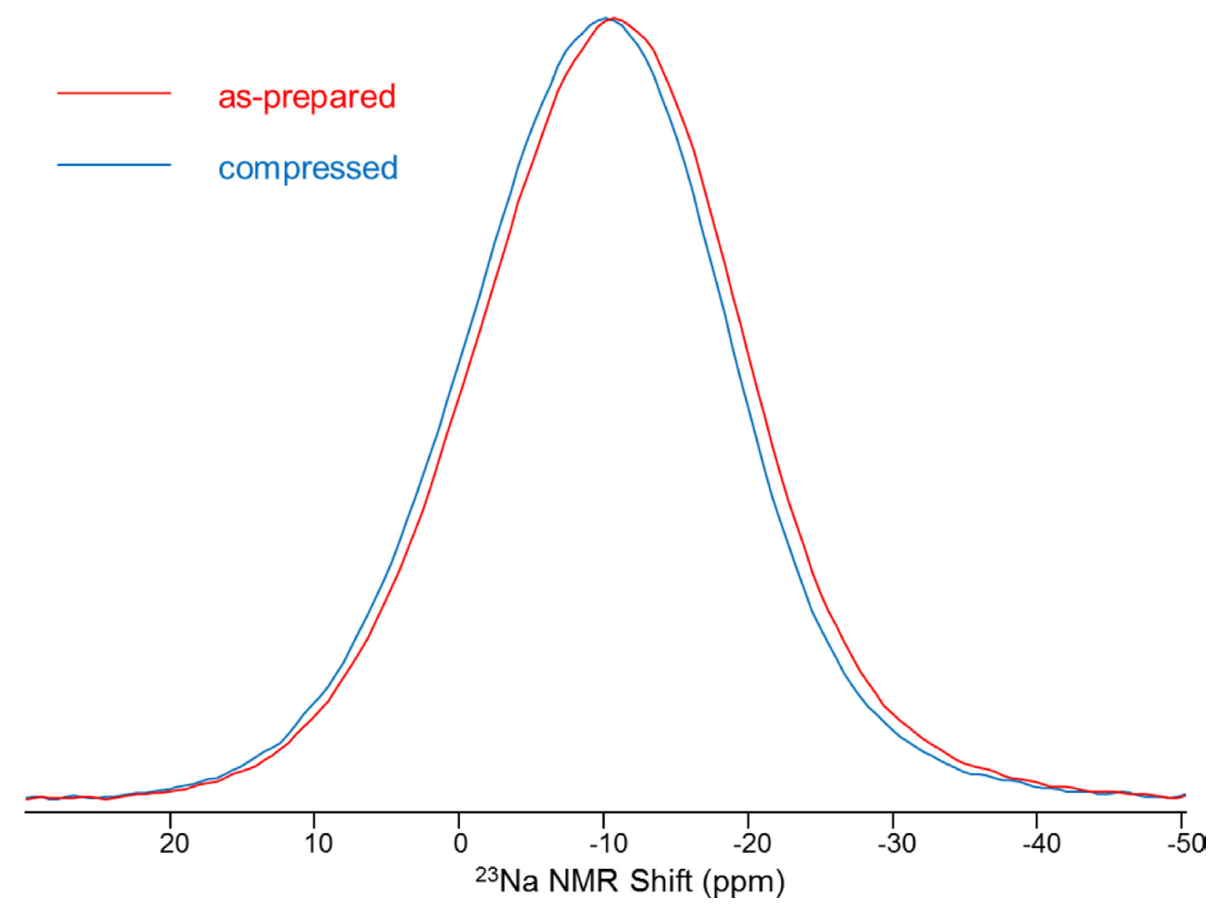

FIGURE 7 | ${ }^{23} \mathrm{Na}$ magic angle spinning nuclear magnetic resonance spectra for Na-borosilicate at 1 atm and $1 \mathrm{GPa}$. Reprinted figure with permission from Svenson et al. (2014a). Copyright (2014) by the American Physical Society.

same set of glasses to understand the origin of the frequency shift (Svenson et al., 2014a). Evaluation of 3Q MAS NMR data, using the center of gravity in both the MAS and isotropic shift dimension, indicates that compression leads to a change in chemical shift $\left(\delta_{\text {iso }}\right)$ only, with the quadrupolar coupling product $\left(P_{\mathrm{Q}}\right)$ remaining relatively constant. This implies that the average $\mathrm{Na}-\mathrm{O}$ distance decreases with pressure, accompanied by a reduction in the partial molar volume of $\mathrm{Na}_{2} \mathrm{O}$, but likely without any change in sodium coordination number (George and Stebbins, 1996; Lee and Stebbins, 2003; Wu et al., 2009). This is also consistent with studies of sodium environment in glasses compressed at much higher pressures (Lee, 2010). On the contrary, a later study on Na-aluminosilicate glass using ${ }^{23} \mathrm{Na} 3 \mathrm{Q}$ MAS NMR revealed that changes in $P_{\mathrm{Q}}$ with compression are significant and account for at least a part of the shift in the MAS peak position (Svenson et al., $2014 \mathrm{~b})$. Changes in $P_{\mathrm{Q}}$ are sensitive to the symmetry around the $\mathrm{Na}^{+}$site, and compression tends to enhance the symmetric bonding environment of $\mathrm{Na}^{+}$(Svenson et al., 2014b). Furthermore, pressure-induced changes in the chemical shift are found to be directly proportional to the applied pressure (Wu et al., 2009; Smedskjaer et al., 2014b).

\section{Intermediate-Range Order}

Following the observations of decoupling of pressure- and temperature-induced property changes (Wondraczek and Behrens, 2007; Wondraczek et al., 2007b), ongoing efforts have been focused on elucidating the effect of pressure-freezing on structural order, on intermediate length scale. That is, it was found that short-range structural features such as the coordination number of network formers do not follow the same $p$-T-t-path as macroscopic properties, which are typically associated with longer-ranging structural parameters, e.g., free volume and density. Subsequent considerations therefore concerned the evolution of structural heterogeneity on the Boson scale, assuming that variations in melt pressure directly affect dynamic heterogeneity of the melt. While the evolution of the Boson peak with variations in fictive temperature is still debated (Chemarin et al., 1997; Shimodaira et al., 2005), it was shown that the structural homogeneity of glasses increases with increasing melt pressurization (Champagnon et al., 2009; Mantisi et al., 2010; Reibstein et al., 2011). This seems to reflect the preferential compaction of regions with lower elastic modulus versus more rigid areas, on a length scale of 1-2 nm. It was suggested that the accompanying reduction in light scattering may be of interest for low-loss optical fiber. In addition, potential relations to non-isostatic compaction such as that occurring locally during mechanical contact and damage infliction remain to be elucidated (Wondraczek et al., 2011).

\section{PRESSURE-INDUCED CHANGES IN PROPERTIES}

\section{Extent of Densification}

Compression offers a new route to balance different properties when varying composition and pressure/temperature, which may have important practical implications. The extent of change in the properties of densified glasses is expected to be controlled by the extent of densification and degree of structural changes. To 
compare the extent of pressure-driven densification in different glass compositions and at different applied pressures, we here refer to the irreversible plastic compressibility $(\beta)$ (Smedskjaer et al., 2014b),

$$
\beta=-\frac{1}{V} \cdot \frac{d V}{d P},
$$

where $V$ is the initial volume of the glass before densification and $d V$ is the volume change measured after decompression to ambient conditions.

When a homogeneous isotropic solid such as glass is subjected to hydrostatic pressure, the change of dimensions should be a function of the pressure and temperature only, if the solid is perfectly elastic (Sakka and Mackenzie, 1969). Generally, the plastic compressibility of glasses increases with increasing temperature. However, an earlier study has reported a decrease in plastic compressibility with an increase in temperature in case of fused silica (Birch and Dow, 1936). Like any other property in glasses, plastic compressibility is also influenced by the composition. Weir and Shartsis $(1955,1956)$ showed a decrease in the plastic compressibility with addition of modifiers in alkali silicate, alkali borates, and alkaline-earth borate glasses. This is likely due to the filling up of the network interstices of the glasses. In comparison to the alkaline-earth cations, alkali-containing glasses exhibit lower compressibility because, at equimolar compositions, there are also twice the numbers of alkali ions than alkaline-earth ions, which fill up the interstices faster.

The so-called mixed modifier effect (MME) has also been found to affect the plastic compressibility in $\mathrm{SiO}_{2}-\mathrm{Al}_{2} \mathrm{O}_{3}-\mathrm{Na}_{2} \mathrm{O}$ $\mathrm{MgO}-\mathrm{CaO}$ glasses that have been compressed at $T_{\mathrm{g}}$ (Smedskjaer et al., 2014a). This manifestation of MME has been discussed based on localized network relaxation, facilitating the exchange of cationic sites among $\mathrm{Ca}^{2+}$ and $\mathrm{Mg}^{2+}$ ions. In addition to the influence of modifier ions, plastic compressibility is correlated with the pressure-induced increase in the coordination number of the network-forming cations (Striepe et al., 2013). However, it has been shown that the change in the speciation of network formers alone cannot account for the complete density change. For example, Wu et al. (2009) have estimated that the boron coordination change in compressed E-glass contributes only about $15 \%$ to the overall density difference, due to relatively small difference in the partial volume of $\mathrm{BO}_{3}$ and $\mathrm{BO}_{4}$ structural groups. Although there are no clear trends in the composition dependence of plastic compressibility, some of the factors that should influence plastic compressibility include density, atomic packing fraction (APF, which is the ratio minimum theoretical volume occupied by the ions and corresponding molar volume of the glass), and content of NBOs. In a series of Na-borate glasses, Striepe et al. (2013) observed a negative correlation between the plastic compressibility and density or APF of the ambient conditions glasses. On the other hand, the initial density of the glasses does not appear to influence the plastic compressibility (Aakermann et al., 2015), i.e., a glass with a higher density can possess higher plastic compressibility than a glass with lower density. This has been reported to be positively dependent on the APF of the glasses (Aakermann et al., 2015). However, one cannot always consider APF as the controlling parameter, since plastic compressibility has also been reported to be positively correlated to $\mathrm{NBO} / \mathrm{T}$ in the case of aluminosilicate glasses. Thus, the aluminosilicate glasses with a higher number of NBOs have a greater ability to undergo densification (Bechgaard et al., 2016).

\section{Elastic Moduli}

Elastic moduli quantify the resistance of materials to elastic deformation. In the case of oxide glasses, high elastic moduli are often desirable, e.g., for the production of thinner and stiffer sheets for windows in cars and buildings, substrates for thin film electronics, cover screens for smartphones, light-guide plates for edge-lit displays, and substrates for high-speed magnetic memory disks (Rouxel, 2007; Rosales-Sosa et al., 2015).

The effect of pressure on elastic moduli of binary $\mathrm{PbO}-\mathrm{SiO}_{2}$ glasses has been investigated by Yoshimoto et al. (1989). A positive correlation between elastic moduli and applied pressure was reported, and the elastic moduli were found to be more sensitive to temperature variation upon densification. A similar scaling of elastic moduli with pressure has been observed for a series of borate glasses by Hirao et al. (1991). Later Striepe et al. (2013) discussed the influence of compression on the elastic moduli of borate glasses by hot compressing the glasses at 0.1 to $0.57 \mathrm{GPa}$ using Brillouin scattering. The elastic moduli of the Na-borate glasses were found to be positively correlated with the applied pressure (Figure 8A) (Striepe et al., 2013), even at pressures as low as $100 \mathrm{MPa}$. Aakermann et al. (2015) have reported a similar increase of elastic moduli with compression in a series of hot-compressed alkali aluminosilicate glasses. In the densified glasses, the elastic moduli exhibit linear dependence on the $\left[\mathrm{K}_{2} \mathrm{O}\right] /\left(\left[\mathrm{Na}_{2} \mathrm{O}\right]+\left[\mathrm{K}_{2} \mathrm{O}\right]\right)$ ratio, whereas a non-linear compositional scaling is observed in the as-prepared glasses due to MME. Furthermore, the positive correlation between the extent of densification and elastic moduli also holds for densification achieved for cold and hot compression of silica glass (Guerette et al., 2015). Interestingly, below $20 \%$ density increase, hot-compressed silica glass has higher elastic moduli than cold-compressed silica for the identical extent of densification. The difference in elastic moduli between the two types of densification decreases with increasing extent of densification above 20\% (Guerette et al., 2015).

An approximately linear relationship has been observed between the plastic compressibility and the pressure-induced increase in elastic moduli across a variety of glass families, irrespective of the structural transformations during compression that these glasses exhibit owing to their dramatically different chemistries (Figure 8B) (Svenson et al., 2016a). This implies that the pressure-induced changes in elastic moduli are not governed by the specific structural changes resulting from isostatic hot compression of the various glasses up to $1 \mathrm{GPa}$, but rather by the overall degree of network densification, which is a combined effect of changes in SRO and MRO (Svenson et al., 2016a). On the other hand, a study by Deschamps et al. (2014) found that the variation in the elastic moduli is dependent on the compression path taken to reach permanent densification.

\section{Indentation Hardness}

Permanent densification of glasses can be achieved by compressing the glass at pressure ranging from below $1 \mathrm{GPa}$ to above 

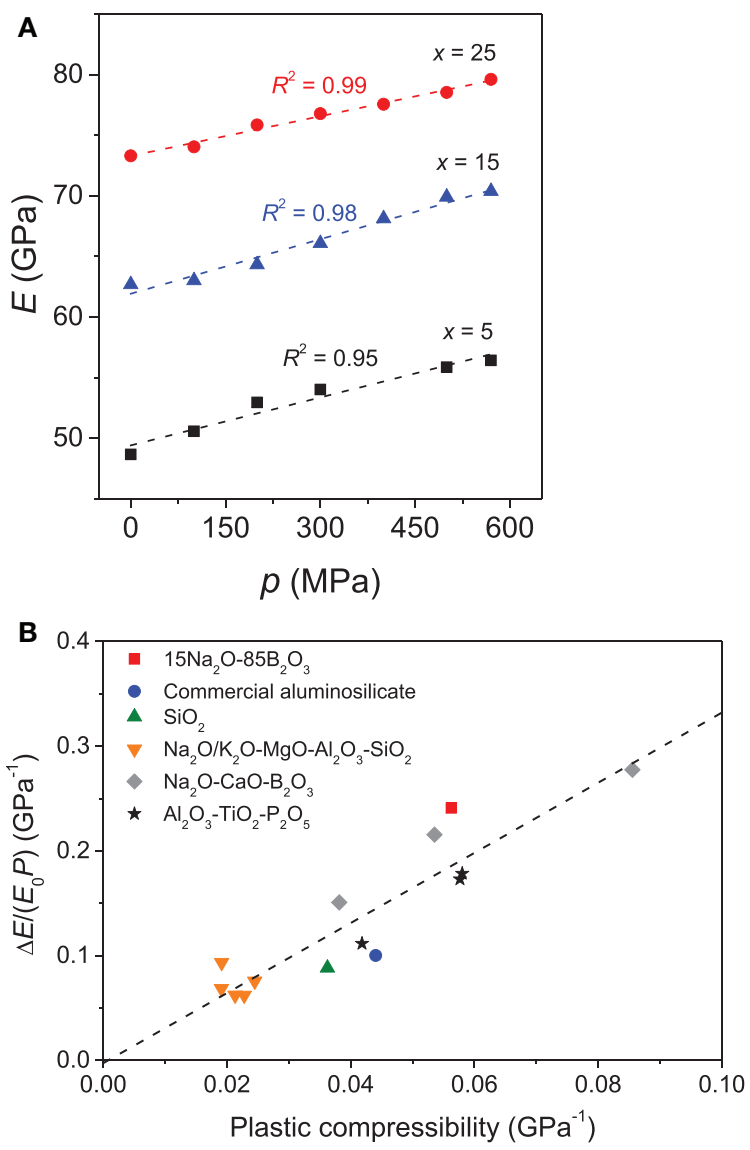

FIGURE 8 | (A) Influence of isostatic pressure (p) on Young's modulus $(E)$ of $x \mathrm{Na}_{2} \mathrm{O} \cdot 10 \mathrm{CaO} \cdot(90-x) \mathrm{B}_{2} \mathrm{O}_{3}$ glasses. The errors associated with the elastic moduli are smaller than the size of the symbols. Reprinted from the study by Striepe et al. (2013), with permission from Elsevier. (B) The normalized change in Young's modulus $\left(\Delta E /\left(E_{0} P\right)\right)$ as a function of plastic compressibility for glasses hot compressed at their respective ambient pressure $T_{\mathrm{g}}$ value. Reprinted from the study by Svenson et al. (2016a), with permission from Elsevier.

$10 \mathrm{GPa}$. Hydrostatic stress of similar intensity develops in glasses under sharp contact loading such as Vickers hardness testing (hardness is a mean value of the contact stress and is typically on the order of a few GPa). Therefore, high-pressure experiments are important for getting insights into the mechanism of the inelastic indentation deformation observed in glasses. Furthermore, as discussed in the preceding sections, high-pressure treatment of glasses can result in changes in the structure of glasses, which should directly affect the mechanical properties of glasses such as hardness, since hardness is sensitive to the local bonding and atomic packing behavior of the constituent atoms and presence of, e.g., NBOs (Bechgaard et al., 2016).

Apart from a few studies in the early 1990s (Yoshimoto et al., 1989; Hirao et al., 1991; Zhang et al., 1995), there has recently been a surge in the studies related to understanding the influence of hot compression on the pressure-induced changes in the mechanical behavior of oxide glasses (Striepe et al., 2013; Smedskjaer et al., 2014a; Bechgaard et al., 2016). High-pressure experiments generally suffer from basic technological problems, most importantly that the pressure limit decreases with increasing diameter of the pressure chamber, traditionally reaching $1 \mathrm{GPa}$ for no more than $20 \mathrm{~mm}$ diameter. This has largely hindered the exploration of industrially relevant mechanical properties, but technological advances have enabled employing larger glass samples $\left(\sim \mathrm{cm}^{2}\right)$, which is essential for reaching a reasonable accuracy for some characterization methods like microindentation. In 1989, Yoshimoto et al. (1989) reported an increase in hardness upon $6 \mathrm{GPa}$ compression at $0.75 \mathrm{~T}_{\mathrm{g}}$ in a series of $\mathrm{PbO}-\mathrm{SiO}_{2}$ glasses. Hirao et al. (1991) later observed a similar increase in the hardness upon compression in a series of alkali borate glasses prepared by applying hydrostatic pressure up to $6 \mathrm{GPa}$ near $T_{\mathrm{g}}$. The increase in hardness was attributed to the decrease of interstitial voids and the increase in fraction of two-dimensional structural groups in the glass network. In addition, to change in hardness, hot compression also facilitates the change in the indentation morphology of the glasses (Zhang et al., 1995). For example, densification around $T_{\mathrm{g}}$ resulted in an increased hardness of a sodium trisilicate glass, along with the easier development of radial cracks (Zhang et al., 1995).

Figure 9A shows the variation in hardness of $\mathrm{Na}_{2} \mathrm{O}-\mathrm{CaO}-\mathrm{B}_{2} \mathrm{O}_{3}$ glasses compressed at different pressures (Striepe et al., 2013). Hardness linearly increases with increasing pressure, but the slope of change in hardness with isostatic pressure $\left(\mathrm{d} H_{\mathrm{v}} / \mathrm{d} p\right)$ is observed to be a function of the glass composition (Figure 9A). Hardness is governed by the degree of network connectivity of the glasses through the average number of rigid bond stretching and bond bending constraints (Smedskjaer et al., 2010). The pressure treatment will change the number of constraints due to increasing network-former coordination numbers, and there will be a greater number of constraints per unit volume. In general, the pressure-induced increase in hardness $\left(\mathrm{d} H_{\mathrm{v}} / \mathrm{d} p\right)$ is higher in glasses with greater plastic compressibility, i.e., easier ability to densify. For example, in the case of $\mathrm{Na}_{2} \mathrm{O}-\mathrm{CaO}-\mathrm{B}_{2} \mathrm{O}_{3}$ glasses (Striepe et al., 2013), $\mathrm{d} H_{\mathrm{v}} / \mathrm{d} p$ is lower for glasses with a higher amount of $\left[\mathrm{Na}_{2} \mathrm{O}\right]$ (Figure 9A), which is attributed to the higher initial concentration of $\mathrm{B}^{\mathrm{IV}}$ units. Thus, a high initial concentration of $\mathrm{B}^{\mathrm{III}}$ units facilitates a higher degree of densification by transforming $\mathrm{B}^{\mathrm{III}}$ to $\mathrm{B}^{\mathrm{IV}}$ upon compression and thus an increase in hardness. In a recent study, the significance of the presence of NBOs in glasses for the pressure-induced change in hardness was reported (Bechgaard et al., 2016), with a positive correlation between the pressure-induced hardness change and $\mathrm{NBO} / \mathrm{T}$ ratio in glasses. In general, the composition dependence of $\mathrm{d} \mathrm{H}_{\mathrm{v}} /$ $\mathrm{d} p$ can be explained by the plastic compressibility of the glasses irrespective of other structural factors, as shown in Figure 9B. This suggests that an overall network densification is responsible for the increase in hardness.

In addition to composition, the hardness of a densified glass also depends on the temperature and time of compression treatment. Østergaard et al. (2015) found that the hardness of a Na-borosilicate glass increases with increase in temperature and time duration of compression after reaching some threshold value (Figure 10A). The data suggest that a critical increase in density is required before the increase in hardness can take place. Interestingly, the hardness changes observed after compression 


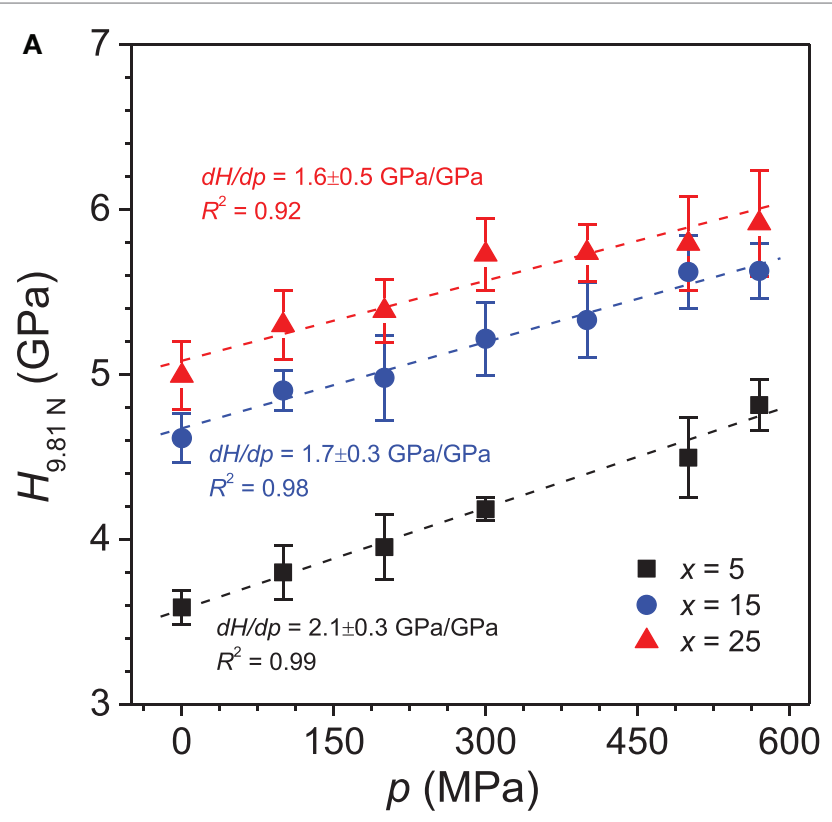

B

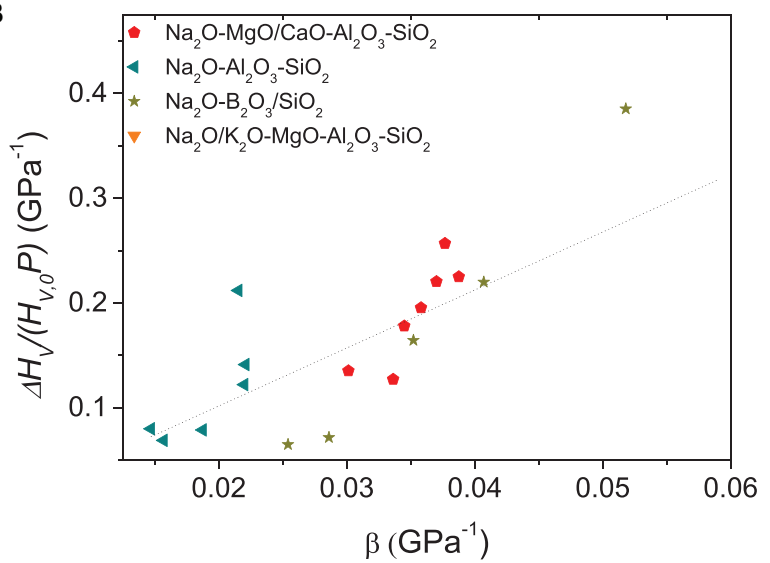

FIGURE 9 | (A) Vickers hardness $\left(H_{v}\right)$ for $x \mathrm{Na}_{2} \mathrm{O} \cdot 10 \mathrm{CaO} \cdot(90-x) \mathrm{B}_{2} \mathrm{O}_{3}$ glasses as a function of the applied isostatic pressure ( $p)$. The hardness is reported for an applied indentation load of $9.81 \mathrm{~N}$. The slopes of the curves $\left(\mathrm{d} / H_{\mathrm{v}} / \mathrm{d} p\right)$ for the three glasses are given in the figure. Reprinted from the study by Striepe et al. (2013), with permission from Elsevier. (B) Relative change in $H_{v}$ measured as a function of plastic compressibility ( $\beta$ ) for a range of oxide glasses. The dotted line is a linear fit to the entire data set. Data are taken from the studies by Smedskjaer (2014), Svenson et al. (2014a), Aakermann et al. (2015), Østergaard et al. (2015).

are influenced by various factors, and $\mathrm{d} H_{\mathrm{v}} / \mathrm{d} p$ can be positive or negative depending on the chemical/thermal treatment of the glasses before or after compression and the compression route followed to densify the glasses. In the case of chemically strengthened glasses subjected to compression, a decrease in hardness as a function of compression temperature was observed, presumably due to the simultaneous relaxation of the compressive stress (CS) generated by the chemical strengthening (Svenson et al., 2014b). The change in hardness also depends on the path taken to densify the glass, such as annealing versus hot compression (Smedskjaer et al., 2015; Svenson et al., 2016c). The volume change brought

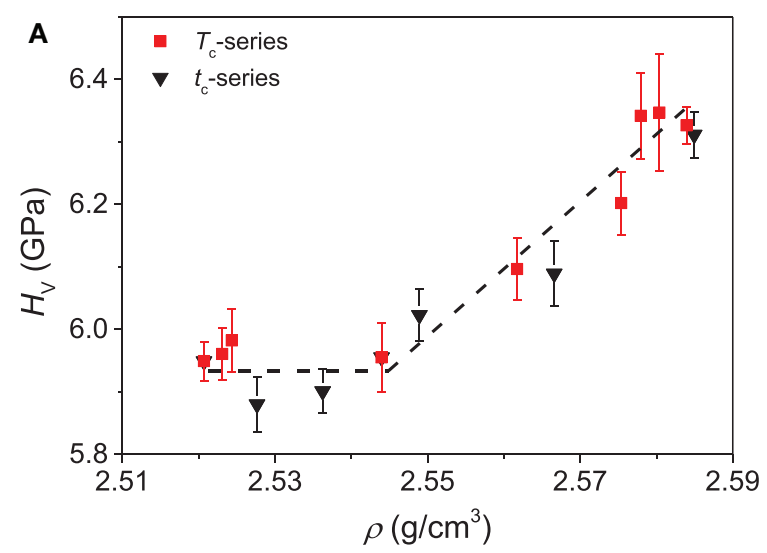

B

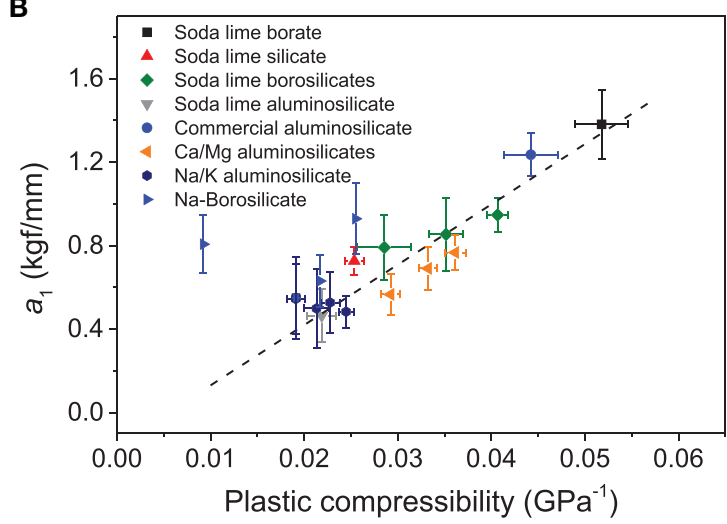

FIGURE 10 | (A) Vickers hardness $\left(H_{\mathrm{V}}\right)$ as a function of density $(\rho)$ for the borosilicate glasses compressed for $30 \mathrm{~min}$ at different temperatures $\left(T_{\mathrm{c}}\right)$ ranging from 0.6 to $1.15 T_{\mathrm{g}}$ and at $0.9 T_{\mathrm{g}}(756 \mathrm{~K})$ for different durations $\left(t_{\mathrm{c}}\right)$ varying from 10 to $10,000 \mathrm{~min}$. The dashed line is a guide for the eye.

Reproduced from the study by Østergaard et al. (2015), with permission from the Royal Society of Chemistry. (B) Extent of the indentation size effect, as quantified through the $a_{1}$ constant of Eq. 7 , as a function of the plastic (irreversible) compressibility. Data are taken from the studies by Smedskjaer (2014), Aakermann et al. (2015), Østergaard et al. (2015).

about by annealing resulted in a greater change in the hardness than equivalent changes brought about by hot compression. This behavior was attributed to the variable structural response toward annealing and pressure quenching as annealing results in more rigid bond angles, thus affecting the SRO, while hot compression mainly affects the $\mathrm{MRO}$ up to $1 \mathrm{GPa}$, which has a smaller effect on the hardness (Smedskjaer et al., 2015).

Compression influences the extent of the indentation size effect (ISE), which is the decrease in hardness with increasing indentation load or size. The origin of the ISE has been widely discussed and variously attributed to, e.g., surface energy (Bernhardt, 1941), friction (Li et al., 1993), subsurface cracking (Swain and Wittling, 1996), and dislocations (Nix and Gao, 1998). The extent of ISE can be quantified using the empirical relation by Bernhardt (1941). Following this approach, the ratio between the indentation load $(P)$ and the indent diagonal length $(l)$ is plotted as a function of $l$,

$$
P / l=a_{1}+a_{2} \times l
$$


where $a_{1}$ is a measure of the extent of the ISE and $a_{2}$ is a measure of the load-independent part of hardness. In a recent investigation, Smedskjaer (2014) compared the qualitative change in $a_{1}$ as a function of plastic compressibility of glasses for various glass systems. The glasses with high plastic compressibility exhibit a larger $a_{1}$ term (Figure 10B), implying a more pronounced ISE. The plausible reason for this behavior was attributed to the fact that glass with higher plastic compressibility will have larger shear band density under pressure, thus will consume more energy in the form of surface energy due to the creation of additional surface and interface.

\section{Viscosity}

Understanding the changes in the melt viscosity at high pressure is of great interest to geologists as the viscosity of igneous melts is one of the most important physical properties controlling the evolution of magmatic systems. The viscosity greatly influences processes such as the ascent of melts in the Earth's mantle and crust, differentiation processes in magma chambers, and the behavior of volcanic eruptions. Hence, there is a fundamental interest in geoscience in predicting viscosities of magmatic systems at various conditions such as high pressure and high temperature. While the compositional and temperature dependence of viscosity is widely established, studies exploring the pressure dependence of viscosity for inorganic glass melts are relatively scarce. In addition, the majority of the studies are performed at high temperature (low viscosity) region, while very few studies have been directed toward the high viscosity regime, i.e., temperature region of $T_{\mathrm{g}}$.

Early efforts to understand the pressure dependence of viscosity in the high viscosity region were made using a centrifugeassisted falling sphere method, where a high-temperature furnace is built into a centrifuge (Dorfman et al., 1996, 1997). This method enabled determination of viscosities up to $10^{8} \mathrm{~Pa}$ s at pressures up to $1 \mathrm{GPa}$. However, the applicability of this technique was limited due to the time scales involved in the measurement, resulting in crystallization in many of the geological relevant melts. To overcome this problem, Schulze et al. (1999) developed a parallel plate viscometer operational in internally heated pressure vessels at pressures up to $0.35 \mathrm{GPa}$ and temperatures up to $1,173 \mathrm{~K}$. The range of viscosity, which could be measured using this setup, is $10^{8.5}-10^{11.5} \mathrm{~Pa}$ s. In a pioneering study on the pressure effect on viscosity near $T_{\mathrm{g}}$, Schulze et al. (1999) performed compression from 0.35 to $0.50 \mathrm{GPa}$ and found an increase in viscosity for diopside and DGG1 (standard soda-lime-silica glass) systems with increasing pressure. This effect of pressure on viscosity is more pronounced in the high viscosity range than in the low viscosity range. For example, when pressure increases from ambient to $0.4 \mathrm{GPa}$, the viscosity of diopside glass-forming liquid increases one order of magnitude at $1,016 \mathrm{~K}$, but only $0.1 \mathrm{log}$ units around 1,800-2,100 K (Behrens and Schulze, 2003).

Furthermore, it was shown that the pressure coefficient increases monotonically with the degree of melt depolymerization, from a negative value for glass-forming albite to a positive value for glass-forming diopside (Behrens and Schulze, 2003). Moreover, the pressure dependence of viscosity of haploandesite melt in the high viscosity region changes from neutral to slightly negative for anhydrous melts and positive for hydrous melts with a water content $>1.06 \mathrm{wt} \%$ (Liebske et al., 2003). Del Gaudio et al. (2007) investigated the pressure dependence of viscosity near $T_{\mathrm{g}}$ up to $0.4 \mathrm{GPa}$ in water-bearing float glass, reporting a negligible effect of pressure on the viscosity of quasi-dry $\left(0.03 \mathrm{wt} \% \mathrm{H}_{2} \mathrm{O}\right)$ and water-bearing $\left(2.14 \% \mathrm{H}_{2} \mathrm{O}\right)$ float glasses. A comparative study using an indirect method of viscosity interpretation from hydrous species reaction at $0.4 \mathrm{GPa}$ found excellent agreement with measurements obtained using parallel-plate viscometer (Hui et al., 2009). Furthermore, Del Gaudio and Behrens (2009) investigated the pressure dependence of alkali- and alkalinesilicate melts. The results indicate that the pressure dependence of viscosity is primarily determined by the melt polymerization degree rather than the chemical composition of the melt, an assumption that was confirmed indirectly also for the case of naturally occurring vitreous silica (Krolikowski et al., 2009).

\section{Chemical Strengthening}

Chemical strengthening or ion exchange strengthening is a posttreatment method to enhance the damage resistance of glasses by creating a near-surface compressive stress (CS) region. To do so, glass is immersed in an electrically heated molten salt bath (e.g., $\mathrm{KNO}_{3}$ ) at temperatures well below $T_{\mathrm{g}}$. An ion exchange between the host alkali ions of the glass and cations from the salt occurs. If the ions entering the glass from the salt bath are larger than the host ions already present in the glass, then the resultant stuffing in a near-rigid atomic network of glass leads to the development of surface compression resulting in an increase in damage resistance (Varshneya, 2010).

Svenson et al. (2014b) studied the ion exchange characteristics, i.e., magnitude and depth of the CS layer, of a commercial Na-Mgaluminosilicate glass $\left(T_{g}=925 \mathrm{~K}\right)$ subjected to compression at an elevated temperature before and after $\mathrm{KNO}_{3}$ ion exchange treatment. The $\mathrm{K}^{+}$concentration profile of the glasses ion exchanged after compression is shown in Figure 11. Compaction of glass at elevated temperature hinders the interdiffusion of $\mathrm{Na}$ and $\mathrm{K}$ ions, leading to a decrease in depth of diffusion and increase in CS due to increasing network dilation coefficient $(B)$, where $B$ is defined as the linear strain of the glass per unit change in alkali concentration. A decrease of alkali diffusivity with network compaction, caused by application of hydrostatic pressure, has also been previously reported (Charles, 1962). However, compression at temperatures at or below $0.7 T_{g}$ prevented the subsequent ion exchange from effectively increasing the hardness of the glass. In contrast, compression of glasses after ion exchange treatment results in an increase in the penetration depth of the $\mathrm{K}^{+}$ ions and decreases the CS of the glass. The plausible reason for this is the thermal annealing during the isostatic compression, which causes inward diffusion of $\mathrm{K}^{+}$ions due to the concentration gradient of the across the sample, which simultaneously decreases the network dilation coefficient. Furthermore, Svenson et al. (2016c) performed a comparative study to understand the influence of different densification methods on the Na-K interdiffusivity. The interdiffusivity was found to increase with increasing ion exchange temperature and decrease with the degree of densification. It is noteworthy that this change in diffusivity is independent of whether the density increase has been obtained 


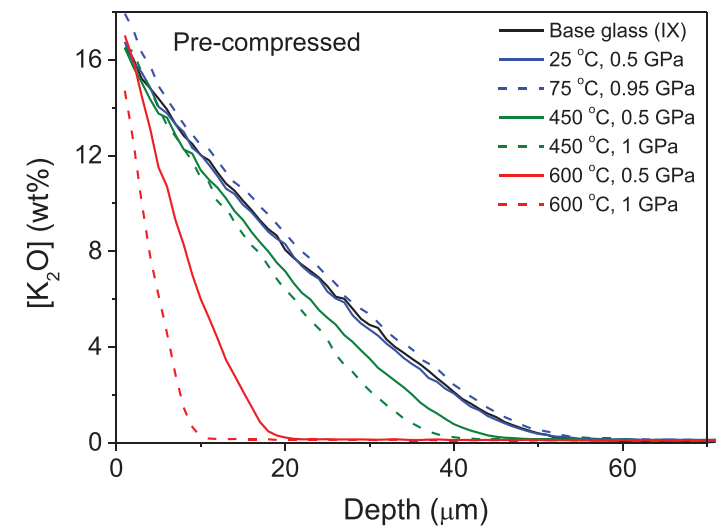

FIGURE $11 \mid \mathrm{K}_{2} \mathrm{O}$ concentration profiles of isostatically compressed samples at different temperatures and pressures (see labels) and then ion exchanged. Reprinted with permission from the study by Svenson et al. (2014b). Copyright (2014) American Chemical Society.

through annealing or compression at elevated temperatures. The activation energy for the densified glasses increases approximately linearly with density irrespective of densification method, since diffusion is governed by the overall network compaction, rather than the specific structural changes facilitating densification during annealing or hot compression.

\section{Chemical Durability}

Chemical durability expresses the resistance of a glass surface toward attack by aqueous solutions and atmospheric agents. Chemical durability of glass is typically estimated by making dissolution experiments by immersing the glass samples in given quantity of fluid and then observing the quantity of materials leached from glass by weight loss measurements or by elemental analysis of the leachate. Such leaching behavior depends on the diffusion ability of the ions in the glass, which primarily is determined by the ionic field strength and structure of the glasses.

Densification of glass results in a decrease in the void volumes and changes in SRO and MRO as discussed above. Few studies have reported the influence of densification on chemical durability of glasses. For example, the corrosion behavior of compressed Na-silicate and Na-borate glasses have been investigated by Zhang et al. (1991a,b). In Na-silicate glass, compression up to $5 \mathrm{GPa}$ at $T_{\mathrm{g}}$ results in a decrease of the $\mathrm{Na}^{+}$release rate due to a decrease in the void volume available for water migration into reactive sites. However, the hydrolysis reactivity is observed to increase after compression, as deformation due to compression results in the formation of unstable bonds, which tend to hydrate easily, resulting in higher hydrolysis activity (Zhang et al., 1991b). In the case of binary Na-borate glasses, pressurization results in a decrease in the dissolution rate. This change in dissolution rate upon compression is not uniform for all the compositions and is dependent on the structure and topology of the borate units in the glasses (Zhang et al., 1991a), i.e., glasses with a minimum amount of $\mathrm{Na}_{2} \mathrm{O}$ exhibit the maximum change in dissolution rate, which decreases with the further addition of $\mathrm{Na}_{2} \mathrm{O}$.

\section{RELAXATION BEHAVIOR OF DENSIFIED GLASSES}

The pioneering study on the relaxation behavior of densified oxide glass was done by Bridgman and Šimon (1953) on densified vitreous silica that is subjected to ambient pressure annealing at $703 \mathrm{~K}$. A decrease in the density from 2.61 to $2.40 \mathrm{~g} \mathrm{~cm}^{-3}$ upon annealing of compressed $\mathrm{SiO}_{2}$ glass was observed, while no relaxation effects were observed on $\mathrm{SiO}_{2}$ glass annealed for 1 week at $873 \mathrm{~K}$ (Cohen and Roy, 1961, 1965; Roy and Cohen, 1961). Mackenzie showed that heat treatment of cold-compressed $\mathrm{SiO}_{2}$ glass for $1 \mathrm{~h}$ at temperatures ranging from 473 to $1,173 \mathrm{~K}$ was sufficient to achieve complete density relaxation (Sakka and Mackenzie, 1969). The relaxation rate was observed to be directly proportional to the annealing temperature and the initial density of the sample. Mackenzie concluded that the apparent stability of the densified silica glass investigated by Cohen and Roy is due to the different thermal history of the investigated glasses.

In comparison to silicate glasses, cold-compressed boratebased glasses exhibit pressure relaxation at much lower temperatures, and pure $\mathrm{B}_{2} \mathrm{O}_{3}$ glass was observed to relax even at room temperature (Mackenzie, 1963a,b). Glasses compressed at elevated temperatures generally exhibit greater stability against subsequent annealing compared to the glasses compressed at room temperature. However, the pressure-induced densification is reversible upon heat treatment near $T_{\mathrm{g}}$ and the consequent relaxation is viscosity driven (Wondraczek et al., 2010). Despite the relaxation of various properties of compressed glasses upon annealing, the coordination number of boron and $\mathrm{Na}-\mathrm{O}$ bond length have been reported to be stable upon annealing at $0.9 T_{\mathrm{g}}$ in a hot-compressed soda lime borate glass (Smedskjaer et al., 2014b), although this effect has been found to be composition dependent (Svenson et al., 2016d). Hence, this result suggests that the pressure-induced macroscopic changes are not exclusively due to the SRO change, but also due to the overall atomic packing density and MRO structures in the glasses (Smedskjaer et al., 2014b). In addition, hot-compressed glasses have been found to remain partly densified even if other properties such as hardness (Neely and Mackenzie, 1968; Kato et al., 2010) exhibit complete relaxation, which is unlike what is found for glasses densified at room temperature.

\section{SUMMARY AND OUTLOOK}

The effects of high pressure at room temperature and in the liquid state on oxide glasses have been relatively well investigated in comparison to pressure experiments at temperatures ranging from sub- $T_{g}$ to $T_{g}$. However, the understanding of the pressureinduced changes at $T_{g}$ is important for developing an in-depth understanding of the influence of pressure on the structure and properties of glasses. The present paper has reviewed studies in the open literature, which have investigated the influence of hot compression on the composition-structure-property relationships in oxide glasses. Existing works provide a good understanding of the pressure-induced changes in the structure of the glasses compressed in the rigid and non-rigid state, although advanced studies might reveal unexpected behaviors. Comparatively fewer 
efforts have been directed toward understanding the pressureinduced changes in the glass properties. Here, we have shown that permanent densification of glasses can be achieved at elevated temperatures and at pressures much lower than cold-compressed glasses. Furthermore, such permanent densification at pressure around $1 \mathrm{GPa}$ sets at temperatures above $0.7 T_{g}$ and the degree of densification increases with increasing compression temperature and time, until attaining an approximately constant value for temperatures above $T_{g}$. For glasses compressed at the same temperature/pressure conditions, direct relations between the degree of volume densification and the pressure-induced change in micromechanical properties exist, such as hardness, elastic moduli, and extent of the ISE across a variety of glass families.

Despite this recent progress, many unanswered questions and challenges remain, which should be addressed in order to develop quantitative relationships between macroscopic properties and structures of oxide glasses at high pressure. While experimental evidence for the short-range chemical order have been revealed for the glasses at both ambient and high pressure, several aspects of the chemical disorder are largely unknown at high pressure. The pressure-induced changes in the structural speciation of different network-modifying cations are not well understood, since majority of studies focused on $\mathrm{Na}$-containing glasses due to the ${ }^{23} \mathrm{Na} \mathrm{NMR}$ structural probe. Moreover, revealing medium-range structural changes and nanoscale-heterogeneities in oxide glasses at high pressure and correlating them with property changes is another challenge that should be addressed in future work. Furthermore, our knowledge of the pressure-induced changes at

\section{REFERENCES}

Aakermann, K. G., Januchta, K., Pedersen, J. A., Svenson, M. N., Rzoska, S. J., Bockowski, M., et al. (2015). Indentation deformation mechanism of isostatically compressed mixed alkali aluminosilicate glasses. J. Non Cryst. Solids 426, 175-183. doi:10.1016/j.jnoncrysol.2015.06.028

Abe, T. (1952). Borosilicate glasses. J. Am. Ceram. Soc. 35, 284-299. doi:10.1111/ j.1151-2916.1952.tb13051.x

Allwardt, J. R., Poe, B. T., Schmidt, B. C., and Stebbins, J. F. (2003). “Compression mechanisms and temperature effects in high pressure glasses investigated by ${ }^{27} \mathrm{Al}$ MAS and ${ }^{17} \mathrm{O}$ 3QMAS NMR," in EGS-AGU-EUG Joint Assembly, 7757. Abstracts from the meeting held in Nice, France.

Allwardt, J. R., Poe, B. T., and Stebbins, J. F. (2005a). The effect of fictive temperature on $\mathrm{Al}$ coordination in high-pressure $(10 \mathrm{GPa})$ sodium aluminosilicate glasses. Am. Miner. 90, 1453-1457. doi:10.2138/am.2005.1736

Allwardt, J. R., Stebbins, J. F., Schmidt, B. C., Frost, D. J., Withers, A. C., and Hirschmann, M. M. (2005b). Aluminum coordination and the densification of high-pressure aluminosilicate glasses. Am. Miner. 90, 1218-1222. doi:10.2138/ am.2005.1836

Allwardt, J. R., Schmidt, B. C., and Stebbins, J. F. (2004). Structural mechanisms of compression and decompression in high-pressure $\mathrm{K}_{2} \mathrm{Si}_{4} \mathrm{O}_{9}$ glasses: an investigation utilizing Raman and NMR spectroscopy of glasses and crystalline materials. Chem. Geol. 213, 137-151. doi:10.1016/j.chemgeo.2004. 08.038

Allwardt, J. R., Stebbins, J. F., Terasaki, H., Du, L. S., Frost, D. J., Withers, A. C., et al. (2007). Effect of structural transitions on properties of high-pressure silicate melts: ${ }^{27} \mathrm{Al} \mathrm{NMR}$, glass densities, and melt viscosities. Am. Miner. 92, 1093-1104. doi:10.2138/am.2007.2530

Angell, C. A., Cheeseman, P. A., and Tamaddon, S. (1982). Pressure enhancement of ion mobilities in liquid silicates from computer simulation studies to 800 kilobars. Science 218, 885-887. doi:10.1126/science.218.4575.885 elevated temperatures is at a premature stage, i.e., the pressure studies at elevated temperatures should be extended to other glass families such as phosphates, germinates, and multicomponent glasses devoid of NBOs to understand the effect of compositions on structure and densification mechanisms in such glasses.

Since the application of pressure at elevated temperatures enables large size samples to be processed, this technique has the potential to be industrialized for commercial purpose to tailor the chemical durability, mechanical properties of glasses. Thus, substantial efforts are needed in future to develop safe experimental facilities, which could be used to compress glass samples of sufficiently large size to be used commercially.

\section{AUTHOR CONTRIBUTIONS}

All the authors contributed to the writing of the manuscript.

\section{ACKNOWLEDGMENTS}

The authors thank M. Bauchy, H. Behrens, M. Bockowski, B. Champagnon, J. Deubener, L. Huang, J. C. Mauro, S. J. Rzoska, M. N. Svenson, R. E. Youngman, and Y. Z. Yue for the fruitful collaboration and inspiring discussions over the recent years in the area of permanent densification. MS acknowledges funding from the Danish Council for Independent Research under Sapere Aude: DFF-Starting Grant (1335-00051A). LW and MS acknowledge support through the priority program PP 1594 of the German Science Foundation (grant no. WO1220/8-1).

Atake, T., and Angell, C. A. (1979). Pressure-dependence of the glass-transition temperature in molecular liquids and plastic crystals. J. Phys. Chem. 83, 3218-3223. doi:10.1021/J100488a007

Bechgaard, T. K., Goel, A., Youngman, R. E., Mauro, J. C., Rzoska, S. J., Bockowski, M., et al. (2016). Structure and mechanical properties of compressed sodium aluminosilicate glasses: role of non-bridging oxygens. J. Non Cryst. Solids 441, 49-57. doi:10.1016/j.jnoncrysol.2016.03.011

Behrens, H., and Schulze, F. (2003). Pressure dependence of melt viscosity in the system $\mathrm{NaAlSi}_{3} \mathrm{O}_{8}-\mathrm{CaMgSi}_{2} \mathrm{O}_{6}$. Am. Miner. 88, 1351-1363. doi:10.2138/ am-2003-8-919

Bernhardt, E. (1941). On microhardness of solids at the limit of Kick's similarity law. Z. Metallkd. 33, 135-144.

Birch, F., and Dow, R. B. (1936). Compressibility of rocks and glasses at high temperatures and pressures: seismological application. Geol. Soc. Am. Bull. 47, 1235-1255. doi:10.1130/GSAB-47-1235

Bista, S., Morin, E. I., and Stebbins, J. F. (2016). Response of complex networks to compression: $\mathrm{Ca}, \mathrm{La}$, and $\mathrm{Y}$ aluminoborosilicate glasses formed from liquids at 1 to 3 GPa pressures. J. Chem. Phys. 144, 044502. doi:10.1063/1.4940691

Bista, S., Stebbins, J. F., Hankins, W. B., and Sisson, T. W. (2015). Aluminosilicate melts and glasses at 1 to $3 \mathrm{GPa}$ : temperature and pressure effects on recovered structural and density changes. Am. Miner. 100, 2298-2307. doi:10.2138/ am-2015-5258

Bottinga, Y., and Richet, P. (1995). Silicate melts: the "anomalous" pressure dependence of the viscosity. Geochim. Cosmochim. Acta 59, 2725-2731. doi:10.1016/0016-7037(95)00168-Y

Boyd, F. R., and England, L. J. (1960). Apparatus for phase-equilibrium measurements at pressures up to 50 kilobars and temperatures up to $1750^{\circ} \mathrm{C}$. J. Geophys. Res. 65, 741-748. doi:10.1029/JZ065i002p00741

Brandriss, M. E., and Stebbins, J. F. (1988). Effects of temperature on the structures of silicate liquids: ${ }^{29} \mathrm{Si}$ NMR results. Geochim. Cosmochim. Acta 52, 2659-2669. doi:10.1016/0016-7037(88)90034-8 
Brawer, S. A., and White, W. B. (1975). Raman spectroscopic investigation of the structure of silicate glasses. I. The binary alkali silicates. J. Chem. Phys. 63, 2421-2432. doi:10.1063/1.431671

Brawer, S. A., and White, W. B. (1977). Raman spectroscopic investigation of the structure of silicate glasses (II). Soda-alkaline earth-alumina ternary and quaternary glasses. J. Non Cryst. Solids 23, 261-278. doi:10.1016/00223093(77)90009-6

Bray, P. J. (1985). Nuclear magnetic resonance studies of glass structure. J. Non Cryst. Solids 73, 19-45. doi:10.1016/0022-3093(85)90335-7

Brazhkin, V. V., Farnan, I., Funakoshi, K.-I., Kanzaki, M., Katayama, Y., Lyapin, A., et al. (2010). Structural transformations and anomalous viscosity in the $\mathrm{B}_{2} \mathrm{O}_{3}$ melt under high pressure. Phys. Rev. Lett. 105, 115701. doi:10.1103/ PhysRevLett.105.115701

Bridgman, P. W., and Šimon, I. (1953). Effects of very high pressures on glass. J. Appl. Phys. 24, 405-413. doi:10.1063/1.1721294

Brown, G. E. J., Farges, F., and Calas, G. (1995). "X-ray scattering and X-ray spectroscopy studies of silicate melts," in Structure, Dynamics and Properties of Silicate Melts, eds J. F. Stebbins, P. F. McMillan, and D. B. Dingwell (Washington, DC: Mineralogical Society of America), 317-410.

Champagnon, B., Martinet, C., Boudeulle, M., Vouagner, D., Coussa, C., Deschamps, T., et al. (2008). High pressure elastic and plastic deformations of silica: in situ diamond anvil cell Raman experiments. J. Non Cryst. Solids 354, 569-573. doi:10.1016/j.jnoncrysol.2007.07.079

Champagnon, B., Wondraczek, L., and Deschamps, T. (2009). Boson peak, structural inhomogeneity, light scattering and transparency of silicate glasses. J. Non Cryst. Solids 355, 712-714. doi:10.1016/j.jnoncrysol.2009.01.029

Charles, R. J. (1962). Structural state and diffusion in a silicate glass. J. Am. Ceram. Soc. 45, 105-113. doi:10.1111/j.1151-2916.1962.tb11094.x

Chason, E., and Spaepen, F. (1988). Pressure-induced structural changes in boron oxide glass. J. Appl. Phys. 64, 4435-4449. doi:10.1063/1.341266

Chemarin, C., Champagnon, B., and Panczer, G. (1997). Effect of fictive temperature on medium range order in $v$-SiO 2 . J. Non Cryst. Solids 216, 111-115. doi:10.1016/S0022-3093(97)00177-4

Chen, J., Wang, Y., Duffy, S. T., Shen, G., and Dobrzhinetskaya, L. F. (2011). Advances in High-Pressure Techniques for Geophysical Applications. Amsterdam: Elsevier.

Cohen, H. M., and Roy, R. (1961). Effects of ultra high pressures on glass. J. Am. Ceram. Soc. 44, 523-524. doi:10.1111/j.1151-2916.1961.tb13717.x

Cohen, H. M., and Roy, R. (1965). Densification of glass at very high pressure. Phys. Chem. Glasses 6, 149-161.

Daniel, I., Gillet, P., Poe, B. T., and McMillan, P. F. (1995). In-situ high-temperature Raman spectroscopic studies of aluminosilicate liquids. Phys. Chem Miner. 22, 74-86. doi:10.1007/BF00202467

Dávila, L. P., Caturla, M.-J., Kubota, A., Sadigh, B., de la Rubia, T. D., Shackelford, J. F., et al. (2003). Transformations in the medium-range order of fused silica under high pressure. Phys. Rev. Lett. 91, 205501. doi:10.1103/PhysRevLett.91.205501

Del Gaudio, P., and Behrens, H. (2009). An experimental study on the pressure dependence of viscosity in silicate melts. J. Chem. Phys. 131, 044504. doi:10.1063/1.3169455

Del Gaudio, P., Behrens, H., and Deubener, J. (2007). Viscosity and glass transition temperature of hydrous float glass. J. Non Cryst. Solids 353, 223-236. doi:10.1016/j.jnoncrysol.2006.11.009

Deschamps, T., Margueritat, J., Martinet, C., Mermet, A., and Champagnon, B. (2014). Elastic moduli of permanently densified silica glasses. Sci. Rep. 4, 7193. doi:10.1038/srep07193

Devine, R. A., and Arndt, J. (1987). Si-O bond-length modification in pressuredensified amorphous $\mathrm{SiO}_{2}$. Phys. Rev. B Condens. Matter 35, 9376. doi:10.1103/ PhysRevB.35.9376

Dorfman, A., Dingwell, D. B., and Bagdassarov, N. S. (1997). A rotating autoclave for centrifuge studies: falling sphere viscometry. Eur. J. Mineral. 9, 345-350. doi: $10.1127 /$ ejm $/ 9 / 2 / 0345$

Dorfman, A., Hess, K.-U., and Dingwell, D. (1996). Centrifuge-assisted falling-sphere viscometry. Eur. J. Mineral. 8, 507-514. doi:10.1127/ejm/8/3/0507

Du, L.-S., Allwardt, J. R., Schmidt, B. C., and Stebbins, J. F. (2004). Pressure-induced structural changes in a borosilicate glass-forming liquid: boron coordination, non-bridging oxygens, and network ordering. J. Non Cryst. Solids 337, 196-200. doi:10.1016/j.jnoncrysol.2004.03.115

Edwards, T., Endo, T., Walton, J. H., and Sen, S. (2014). Observation of the transition state for pressure-induced $\mathrm{BO}_{3} \rightarrow \mathrm{BO}_{4}$ conversion in glass. Science 345 , 1027-1029. doi:10.1126/science. 1256224
Farber, D. L., and Williams, Q. (1996). An in situ Raman spectroscopic study of $\mathrm{Na}_{2} \mathrm{Si}_{2} \mathrm{O}_{5}$ at high pressures and temperatures: structures of compressed liquids and glasses. Am. Miner. 81, 273-283. doi:10.2138/am-1996-3-402

Gaudio, S. J., Lesher, C. E., Maekawa, H., and Sen, S. (2015). Linking high-pressure structure and density of albite liquid near the glass transition. Geochim. Cosmochim. Acta 157, 28-38. doi:10.1016/j.gca.2015.02.017

Gaudio, S. J., Sen, S., and Lesher, C. E. (2008). Pressure-induced structural changes and densification of vitreous $\mathrm{MgSiO}_{3}$. Geochim. Cosmochim. Acta 72, 1222-1230. doi:10.1016/j.gca.2007.12.005

George, A. M., and Stebbins, J. F. (1996). Dynamics of Na in sodium aluminosilicate glasses and liquids. Phys. Chem. Miner. 23, 526-534. doi:10.1007/ BF00242002

Ghosh, D. B., Karki, B. B., and Stixrude, L. (2014). First-principles molecular dynamics simulations of $\mathrm{MgSiO}_{3}$ glass: structure, density, and elasticity at high pressure. Am. Miner. 99, 1304-1314. doi:10.2138/am.2014.4631

Grimsditch, M., Polian, A., and Wright, A. C. (1996). Irreversible structural changes in vitreous $\mathrm{B}_{2} \mathrm{O}_{3}$ under pressure. Phys. Rev. B Condens. Matter 54, 152-155. doi:10.1103/PhysRevB.54.152

Guerette, M., Ackerson, M. R., Thomas, J., Yuan, F., Watson, E. B., Walker, D., et al. (2015). Structure and properties of silica glass densified in cold compression and hot compression. Sci. Rep. 5, 15343. doi:10.1038/srep15343

Gupta, P. K. (1988). Fictive pressure effects in structural relaxation. J. Non Cryst. Solids 102, 231-239. doi:10.1016/0022-3093(88)90136-6

Hall, H. T. (1960). Ultra-high-pressure, high-temperature apparatus: the "belt". Rev. Sci. Instrum. 31, 125-131. doi:10.1063/1.1716907

Hirao, K., Zhang, Z., Morita, H., and Soga, N. (1991). Effect of densification treatment on the mechanical properties of borate glasses. J. Soc. Mater. Sci. Jpn. 40, 400-404. doi:10.2472/jsms.40.40

Hochella, M. F. Jr., and Brown, G. E. Jr. (1985). The structures of albite and jadeite composition glasses quenched from high pressure. Geochim. Cosmochim. Acta 49, 1137-1142. doi:10.1016/0016-7037(85)90004-3

Huang, L., and Kieffer, J. (2004). Amorphous-amorphous transitions in silica glass. II. Irreversible transitions and densification limit. Phys. Rev. B 69, 224204. doi:10.1103/PhysRevB.69.224204

Hui, H., Zhang, Y., Xu, Z., Del Gaudio, P., and Behrens, H. (2009). Pressure dependence of viscosity of rhyolitic melts. Geochim. Cosmochim. Acta 73, 3680-3693. doi:10.1016/j.gca.2009.03.035

Inamura, Y., Arai, M., Nakamura, M., Otomo, T., Kitamura, N., Bennington, S. M., et al. (2001). Intermediate range structure and low-energy dynamics of densified vitreous silica. J. Non Cryst. Solids 293-295, 389-393. doi:10.1016/ S0022-3093(01)00824-9

Ito, E. (2007). Theory and practice - multianvil cells and high-pressure experimental methods. Treatise Geophys. 2, 197-230. doi:10.1016/B978-044452748-6. 00036-5

Januchta, K., Youngman, R. E., Goel, A., Rzoska, S. J., Bockowski, M., Bauchy, M., et al. (2017). Structural origin of high crack resistance in sodium aluminoborate glasses. J. Non Cryst. Solids 460, 54-65. doi:10.1016/j.jnoncrysol.2017. 01.019

Jaworski, A., Stevensson, B., and Edén, M. (2016). The bearings from rare-earth $(\mathrm{RE}=\mathrm{La}, \mathrm{Lu}, \mathrm{Sc}, \mathrm{Y})$ cations on the oxygen environments in aluminosilicate glasses: a study by solid-state ${ }^{17} \mathrm{O} \mathrm{NMR}$, molecular dynamics simulations, and DFT calculations. J. Phys. Chem. C 120, 13181-13198. doi:10.1021/ acs.jpcc.6b02032

Jin, W., Kalia, R. K., Vashishta, P., and Rino, J. P. (1994). Structural transformation in densified silica glass: a molecular-dynamics study. Phys. Rev. B Condens. Matter 50, 118-131. doi:10.1103/PhysRevB.50.118

Kato, Y., Yamazaki, H., Itakura, S., Yoshida, S., and Matsuoka, J. (2011). Load dependence of densification in glass during Vickers indentation test. J. Ceram. Soc. Jpn. 119, 110-115. doi:10.2109/jcersj2.119.110

Kato, Y., Yamazaki, H., Kubo, Y., Yoshida, S., Matsuoka, J., and Akai, T. (2010). Effect of $\mathrm{B}_{2} \mathrm{O}_{3}$ content on crack initiation under Vickers indentation test. J. Ceram. Soc. Jpn. 118, 792-798. doi:10.2109/jcersj2.118.792

Kelsey, K. E., Stebbins, J. F., Singer, D. M., Brown, G. E. Jr., Mosenfelder, J. L., and Asimow, P. D. (2009). Cation field strength effects on high pressure aluminosilicate glass structure: multinuclear NMR and La XAFS results. Geochim. Cosmochim. Acta 73, 3914-3933. doi:10.1016/j.gca.2009.03.040

Krolikowski, S., Brungs, S., and Wondraczek, L. (2009). Relaxation of Libyan desert glass: evidence for negative viscosity-pressure dependence in silica? J. Non Cryst. Solids 355, 1666-1668. doi:10.1016/j.jnoncrysol.2009.06.009 
Kushiro, I. (1976). Changes in viscosity and structure of melt of $\mathrm{NaAlSi}_{2} \mathrm{O}_{6}$ composition at high pressures. J. Geophys. Res. 81, 6347-6350. doi:10.1029/ JB081i035p06347

Kushiro, I. (1978). Viscosity and structural changes of albite $\left(\mathrm{NaAlSi}_{3} \mathrm{O}_{8}\right)$ melt at high pressures. Earth Planet. Sci. Lett. 41, 87-90. doi:10.1016/0012-821X(78) 90044-4

Kushiro, I. (1983). Effect of pressure on the diffusivity of network-forming cations in melts of jadeitic compositions. Geochim. Cosmochim. Acta 47, 1415-1422. doi:10.1016/0016-7037(83)90300-9

Lee, S. K. (2004). Structure of silicate glasses and melts at high pressure: quantum chemical calculations and solid-state NMR. J. Phys. Chem. B 108, 5889-5900. doi:10.1021/jp037575d

Lee, S. K. (2005). Microscopic origins of macroscopic properties of silicate melts and glasses at ambient and high pressure: implications for melt generation and dynamics. Geochim. Cosmochim. Acta 69, 3695-3710. doi:10.1016/ j.gca.2005.03.011

Lee, S. K. (2010). Effect of pressure on structure of oxide glasses at high pressure: insights from solid-state NMR of quadrupolar nuclides. Solid State Nucl. Magn. Reson. 38, 45-57. doi:10.1016/j.ssnmr.2010.10.002

Lee, S. K., Cody, G. D., Fei, Y., and Mysen, B. O. (2004). Nature of polymerization and properties of silicate melts and glasses at high pressure. Geochim. Cosmochim. Acta 68, 4189-4200. doi:10.1016/j.gca.2004.04.002

Lee, S. K., Eng, P. J., Mao, H.-K., Meng, Y., Newville, M., Hu, M. Y., et al. (2005a). Probing of bonding changes in $\mathrm{B}_{2} \mathrm{O}_{3}$ glasses at high pressure with inelastic X-ray scattering. Nat. Mater. 4, 851-854. doi:10.1038/nmat1511

Lee, S. K., Mibe, K., Fei, Y., Cody, G. D., and Mysen, B. O. (2005b). Structure of $\mathrm{B}_{2} \mathrm{O}_{3}$ Glass at High Pressure: a ${ }^{11}$ B Solid-State NMR Study. Phys. Rev. Lett. 94, 165507. doi:10.1103/PhysRevLett.94.165507

Lee, S. K., Lin, J.-F., Cai, Y. Q., Hiraoka, N., Eng, P. J., Okuchi, T., et al. (2008). $\mathrm{X}$-ray Raman scattering study of $\mathrm{MgSiO}_{3}$ glass at high pressure: implication for triclustered $\mathrm{MgSiO}_{3}$ melt in Earth's mantle. Proc. Natl. Acad. Sci. U.S.A. 105, 7925-7929. doi:10.1073/pnas.0802667105

Lee, S. K., and Stebbins, J. F. (2003). The distribution of sodium ions in aluminosilicate glasses: a high-field Na-23 MAS and 3Q MAS NMR study. Geochim. Cosmochim. Acta 67, 1699-1709. doi:10.1016/S0016-7037(03)00026-7

Li, D., Secco, R., Bancroft, G., and Fleet, M. (1995). Pressure induced coordination change of $\mathrm{Al}$ in silicate melts from $\mathrm{Al} \mathrm{K}$ edge XANES of high pressure $\mathrm{NaAlSi}_{2} \mathrm{O}_{6}-\mathrm{NaAlSi}_{3} \mathrm{O}_{8}$ glasses. Geophys. Res. Lett. 22, 3111-3114. doi:10.1029/ 95GL03175

Li, H., Ghosh, A., Han, Y. H., and Bradt, R. C. (1993). The frictional component of the indentation size effect in low load microhardness testing. J. Mater. Res. 8, 1028-1028. doi:10.1557/JMR.1993.1028

Liebske, C., Behrens, H., Holtz, F., and Lange, R. A. (2003). The influence of pressure and composition on the viscosity of andesitic melts. Geochim. Cosmochim. Acta 67, 473-485. doi:10.1016/S0016-7037(02)01139-0

Mackenzie, J. (1963a). High-pressure effects on oxide glasses: I, densification in rigid state. J. Am. Ceram. Soc. 46, 461-470. doi:10.1111/j.1151-2916.1963. tb13776.x

Mackenzie, J. (1963b). High-pressure effects on oxide glasses: II, subsequent heat treatment. J. Am. Ceram. Soc. 46, 470-476. doi:10.1111/j.1151-2916.1963. tb13777.x

Mackenzie, J. (1964). High-pressure effects on oxide glasses: III, densification in nonrigid state. J. Am. Ceram. Soc. 47, 76-80. doi:10.1111/j.1151-2916.1964. tb15659.x

Malfait, W. J., Verel, R., Ardia, P., and Sanchez-Valle, C. (2012). Aluminum coordination in rhyolite and andesite glasses and melts: effect of temperature, pressure, composition and water content. Geochim. Cosmochim. Acta 77, 11-26. doi:10.1016/j.gca.2011.11.011

Mantisi, B., Adichtchev, S., Sirotkin, S., Rafaelly, L., Wondraczek, L., Behrens, H., et al. (2010). Non-Debye normalization of the glass vibrational density of states in mildly densified silicate glasses. J. Phys. Condens. Matter 22, 0254402. doi:10.1088/0953-8984/22/2/025402

Martinet, C., Kassir-Bodon, A., Deschamps, T., Cornet, A., Le Floch, S., Martinez, V., et al. (2015). Permanently densified $\mathrm{SiO}_{2}$ glasses: a structural approach. J. Phys. Condens. Matter 27, 325401. doi:10.1088/0953-8984/27/32/ 325401

Mauro, J. C., and Zanotto, E. D. (2014). Two centuries of glass research: historical trends, current status, and grand challenges for the future. Int. J. Appl. Glass Sci. 5, 313-327. doi:10.1111/ijag.12087
McMillan, P., Piriou, B., and Couty, R. (1984). A Raman study of pressure-densified vitreous silica. J. Chem. Phys. 81, 4234-4236. doi:10.1063/1.447455

McMillan, P. F. (2002). New materials from high-pressure experiments. Nat. Mater. 1, 19-25. doi:10.1038/nmat716

McMillan, P. F., and Graham, C. M. (1980). "The Raman spectra of quenched albite and orthoclase glasses from $1 \mathrm{~atm}$ to $40 \mathrm{~kb}$," in Progress in Experimental Petrology, ed. C. E.Ford (Boston, MA: Eaton Press), 112-115.

McMillan, P. F., and Wolf, G. H. (1995). Vibrational spectroscopy of silicate liquids. Rev. Mineral. Geochem. 32, 247-315.

Morin, E. I., Wu, J., and Stebbins, J. F. (2014). Modifier cation (Ba, Ca, La, Y) field strength effects on aluminum and boron coordination in aluminoborosilicate glasses: the roles of fictive temperature and boron content. Appl. Phys. A 116, 479-490. doi:10.1007/s00339-014-8369-4

Murdoch, J. B., Stebbins, J. F., and Carmichael, I. S. E. (1985). High-resolution ${ }^{29} \mathrm{Si}$ NMR study of silicate and aluminosilicate glasses: the effect of networkmodifying cations. Am. Miner. 70, 332-343.

Mysen, B. O. (1988). Structure and Properties of Silicate Melts. Amsterdam: Elsevier.

Mysen, B. O., and Richet, P. (2005). Silicate Glasses and Melts: Properties and Structure. Amsterdam: Elsevier.

Mysen, B. O., Virgo, D., and Scarfe, C. M. (1980). Relations between the anionic structure and viscosity of silicate melts - a Raman spectroscopic study. Am. Miner. 65, 690-710.

Naji, M., De Sousa Meneses, D., Guimbretière, G., and Vaills, Y. (2015). In situ high-temperature probing of the local order of a silicate glass and melt during structural relaxation. J. Phys. Chem. C 119, 8838-8848. doi:10.1021/ jp512234k

Navrotsky, A., Peraudeau, G., McMillan, P., and Coutures, J.-P. (1982). A thermochemical study of glasses and crystals along the joins silica-calcium aluminate and silica-sodium aluminate. Geochim. Cosmochim. Acta 46, 2039-2047. doi:10.1016/0016-7037(82)90183-1

Neely, J. E., and Mackenzie, J. D. (1968). Hardness and low-temperature deformation of silica glass. J. Mater. Sci. 3, 603-609. doi:10.1007/BF00757906

Neuville, D. R., and Richet, P. (1991). Viscosity and mixing in molten (Ca, $\mathrm{Mg}$ ) pyroxenes and garnets. Geochim. Cosmochim. Acta 55, 1011-1019. doi:10.1016/0016-7037(91)90159-3

Nix, W. D., and Gao, H. (1998). Indentation size effects in crystalline materials: a law for strain gradient plasticity. J. Mech. Phys. Sol. 46, 411-425. doi:10.1016/ S0022-5096(97)00086-0

Østergaard, M. B., Youngman, R. E., Svenson, M. N., Rzoska, S. J., Bockowski, M., Jensen, L. R., et al. (2015). Temperature-dependent densification of sodium borosilicate glass. RSC Adv. 5, 78845-78851. doi:10.1039/C5RA16219J

Poe, B. T., McMillan, P. F., Rubie, D. C., Chakraborty, S., Yarger, J., and Diefenbacher, J. (1997). Silicon and oxygen self-diffusivities in silicate liquids measured to 15 gigapascals and 2800 Kelvin. Science 276, 1245-1248. doi:10.1126/ science.276.5316.1245

Poe, B. T., Romano, C., and Henderson, G. (2004). Raman and XANES spectroscopy of permanently densified vitreous silica. J. Non Cryst. Solids 341, 162-169. doi:10.1016/j.jnoncrysol.2004.04.014

Poe, B. T., Romano, C., Zotov, N., Cibin, G., and Marcelli, A. (2001). Compression mechanisms in aluminosilicate melts: Raman and XANES spectroscopy of glasses quenched from pressures up to $10 \mathrm{GPa}$. Chem. Geol. 174, 21-31. doi:10.1016/S0009-2541(00)00304-1

Reibstein, S., Wondraczek, L., de Ligny, D., Krolikowski, S., Sirotkin, S., Simon, J. P., et al. (2011). Structural heterogeneity and pressure-relaxation in compressed borosilicate glasses by in situ small angle X-ray scattering. J. Chem. Phys. 134, 204502. doi:10.1063/1.3593399

Rosales-Sosa, G. A., Masuno, A., Higo, Y., Inoue, H., Yanaba, Y., Mizoguchi, T., et al. (2015). High elastic moduli of a $54 \mathrm{Al}_{2} \mathrm{O}_{3}-46 \mathrm{Ta}_{2} \mathrm{O}_{5}$ glass fabricated via containerless processing. Sci. Rep. 5, 15233. doi:10.1038/srep15233

Rouxel, T. (2007). Elastic properties and short-to medium-range order in glasses. J. Am. Ceram. Soc. 90, 3019-3039. doi:10.1111/j.1551-2916.2007.01945.x

Roy, R., and Cohen, H. M. (1961). Effects of high pressure on glass: a possible piezometer for the 100-kilobar region. Nature 190, 798-799. doi:10.1038/ $190798 \mathrm{a} 0$

Sakka, S., and Mackenzie, J. D. (1969). High pressure effects on glass. J. Non Cryst. Solids 1, 107-142. doi:10.1016/0022-3093(69)90012-X

Salmon, P. S., Drewitt, J. W. E., and Zeidler, A. (2016). Neutron diffraction as a probe of liquid and glass structures under extreme conditions. Neutron News 27, 22-26. doi:10.1080/10448632.2016.1197592 
Salmon, P. S., and Zeidler, A. (2015). Networks under pressure: the development of in situ high-pressure neutron diffraction for glassy and liquid materials. J. Phys. Condens. Matter 27, 133201. doi:10.1088/0953-8984/27/13/133201

Sato, T., Funamori, N., and Yagi, T. (2011). Helium penetrates into silica glass and reduces its compressibility. Nat. Commun. 2, 345. doi:10.1038/ncomms 1343

Schulze, F., Behrens, H., and Hurkuck, W. (1999). Determination of the influence of pressure and dissolved water on the viscosity of highly viscous melts: application of a new parallel-plate viscometer. Am. Miner. 84, 1512-1520. doi:10.2138/am-1999-1004

Sharma, S. K., Virgo, D., and Mysen, B. O. (1979). Raman study of the coordination of aluminum in jadeite melts as a function of pressure. Am. Miner. 64, 779-787.

Shelby, J. E. (2005). Introduction to Glass Science and Technology. Cambridge: Royal Society of Chemistry.

Shimizu, N., and Kushiro, I. (1984). Diffusivity of oxygen in jadeite and diopside melts at high pressures. Geochim. Cosmochim. Acta 48, 1295-1303. doi:10.1016/0016-7037(84)90063-2

Shimodaira, N., Saito, K., Hiramitsu, N., Matsushita, S., and Ikushima, A. (2005). Effects of fictive temperature and halogen doping on the boson peak in silica glass. Phys. Rev. B 71, 024209. doi:10.1103/PhysRevB.71.024209

Smedskjaer, M. M. (2014). Indentation size effect and the plastic compressibility of glass. Appl. Phys. Lett. 104, 251906. doi:10.1063/1.4885337

Smedskjaer, M. M., Bauchy, M., Mauro, J. C., Rzoska, S. J., and Bockowski, M. (2015). Unique effects of thermal and pressure histories on glass hardness: structural and topological origin. J. Chem. Phys. 143, 164505. doi:10.1063/1.4934540

Smedskjaer, M. M., Mauro, J. C., and Yue, Y. (2010). Prediction of glass hardness using temperature-dependent constraint theory. Phys. Rev. Lett. 105, 115503. doi:10.1103/PhysRevLett.105.115503

Smedskjaer, M. M., Rzoska, S. J., Bockowski, M., and Mauro, J. C. (2014a). Mixed alkaline earth effect in the compressibility of aluminosilicate glasses. J. Chem. Phys. 140, 054511. doi:10.1063/1.4863998

Smedskjaer, M. M., Youngman, R. E., Striepe, S., Potuzak, M., Bauer, U., Deubener, J., et al. (2014b). Irreversibility of pressure induced boron speciation change in glass. Sci. Rep. 4, 3770. doi:10.1038/srep03770

Sonneville, C., De Ligny, D., Mermet, A., Champagnon, B., Martinet, C., Henderson, G. H., et al. (2013). In situ Brillouin study of sodium alumino silicate glasses under pressure. J. Chem. Phys. 139, 074501. doi:10.1063/1.4818335

Spera, F. J., Nevins, D., Ghiorso, M., and Cutler, I. (2009). Structure, thermodynamic and transport properties of $\mathrm{CaAl}_{2} \mathrm{Si}_{2} \mathrm{O}_{8}$ liquid. Part I: molecular dynamics simulations. Geochim. Cosmochim. Acta 73, 6918-6936. doi:10.1016/ j.gca.2009.08.011

Stebbins, J. F., and Mcmillan, P. (1989). Five- and six-coordinated $\mathrm{Si}$ in $\mathrm{K}_{2} \mathrm{Si}_{4} \mathrm{O}_{9}$ glass quenched 1.9 GPa and $1200^{\circ} \mathrm{C}$. Am. Miner. 74, 965-968.

Striepe, S., Smedskjaer, M. M., Deubener, J., Bauer, U., Behrens, H., Potuzak, M., et al. (2013). Elastic and micromechanical properties of isostatically compressed soda-lime-borate glasses. J. Non Cryst. Solids 364, 44-52. doi:10.1016/ j.jnoncrysol.2013.01.009

Svenson, M. N., Bechgaard, T. K., Fuglsang, S. D., Pedersen, R. H., Tjell, A. Ø, Østergaard, M. B., et al. (2014a). Composition-structure-property relations of compressed borosilicate glasses. Phys. Rev. Appl. 2, 024006. doi:10.1103/ PhysRevApplied.2.024006

Svenson, M. N., Thirion, L. M., Youngman, R. E., Mauro, J. C., Rzoska, S. J., Bockowski, M., et al. (2014b). Pressure-induced changes in interdiffusivity and compressive stress in chemically strengthened glass. ACS Appl. Mater. Interfaces 6, 10436-10444. doi:10.1021/am5019868

Svenson, M. N., Guerette, M., Huang, L., Lönnroth, N., Mauro, J. C., Rzoska, S. J., et al. (2016a). Universal behavior of changes in elastic moduli of hot compressed oxide glasses. Chem. Phys. Lett. 651, 88-91. doi:10.1016/j.cplett.2016.03.025

Svenson, M. N., Guerette, M., Huang, L., and Smedskjaer, M. M. (2016b). Raman spectroscopy study of pressure-induced structural changes in sodium borate glass. J. Non Cryst. Solids 443, 130-135. doi:10.1016/j.jnoncrysol.2016.04.023

Svenson, M. N., Thirion, L. M., Youngman, R. E., Mauro, J. C., Bauchy, M., Rzoska, S. J., et al. (2016c). Effects of thermal and pressure histories on the chemical strengthening of sodium aluminosilicate glass. Front. Mater. 3:14. doi:10.3389/ fmats.2016.00014

Svenson, M. N., Youngman, R. E., Yue, Y., Rzoska, S. J., Bockowski, M., Jensen, L. R., et al. (2016d). Volume and structural relaxation in compressed sodium borate glass. Phys. Chem. Chem. Phys. 18, 29879-29891. doi:10.1039/C6CP06341A

Swain, M. V., and Wittling, M. (1996). Fracture Mechanics of Ceramics, Vol. 11. New York, NY: Plenum Press, 379.
Tammann, G., and Jenckel, E. (1929). Increase in density of glasses after solidifying under high pressure and return to original density with increased temperatures. Z. Anorg. Allgem. Chem. 184, 416-420. doi:10.1002/zaac. 19291840134

Tinker, D., Lesher, C. E., and Hutcheon, I. D. (2003). Self-diffusion of Si and O in diopside-anorthite melt at high pressures. Geochim. Cosmochim. Acta 67, 133-142. doi:10.1016/S0016-7037(02)01039-6

Toplis, M. J., Dingwell, D. B., Hess, K.-U., and Lenci, T. (1997a). Viscosity, fragility, and configurational entropy of melts along the join $\mathrm{SiO}_{2}-\mathrm{NaAlSiO}_{4}$. Am. Miner. 82, 979-990. doi:10.2138/am-1997-9-1014

Toplis, M. J., Dingwell, D. B., and Lenci, T. (1997b). Peraluminous viscosity maxima in $\mathrm{Na}_{2} \mathrm{O}-\mathrm{Al}_{2} \mathrm{O}_{3}-\mathrm{SiO}_{2}$ liquids: the role of triclusters in tectosilicate melts. Geochim. Cosmochim. Acta 61, 2605-2612. doi:10.1016/S0016-7037(97) 00126-9

Trachenko, K., and Dove, M. T. (2002). Densification of silica glass under pressure. J. Phys. Condens. Matter 14, 7449. doi:10.1088/0953-8984/14/32/304

Trachenko, K., and Dove, M. T. (2003). Compressibility, kinetics, and phase transition in pressurized amorphous silica. Phys. Rev. B 67, 064107. doi:10.1103/ PhysRevB.67.064107

Uhlmann, D. R. (1973). Densification of alkali silicate glasses at high pressure. J. Non Cryst. Solids 13, 89-99. doi:10.1016/0022-3093(73)90038-0

Varshneya, A. K. (2010). Chemical strengthening of glass: lessons learned and yet to be learned. Int. J. Appl. Glass Sci. 1, 131-142. doi:10.1111/j.2041-1294.2010. 00010.x

Velde, B., and Kushiro, I. (1978). Structure of sodium alumino-silicate melts quenched at high pressure; infrared and aluminum K-radiation data. Earth Planet. Sci. Lett. 40, 137-140. doi:10.1016/0012-821X(78)90083-3

Waff, H. S. (1975). Pressure-induced coordination changes in magmatic liquids. Geophys. Res. Lett. 2, 193-196. doi:10.1029/GL002i005p00193

Wang, S., and Stebbins, J. F. (1999). Multiple-quantum magic-angle spinning $17 \mathrm{O}$ NMR studies of borate, borosilicate, and boroaluminate glasses. J. Am. Ceram. Soc. 82, 1519-1528. doi:10.1111/j.1151-2916.1999.tb01950.x

Weir, C. E., and Shartsis, L. (1955). Compressibility of binary alkali borate and silicate glasses at high pressures. J. Am. Ceram. Soc. 38, 299-306. doi:10.1111/ j.1151-2916.1955.tb14951.x

Weir, C. E., and Shartsis, L. (1956). Compressibility of binary alkaline-earth borate glasses at high pressures. J. Am. Ceram. Soc. 39, 319-322. doi:10.1111/ j.1151-2916.1956.tb15839.x

Wolf, G. W., and McMillan, P. F. (1995). Pressure effects on silicate melt structure and properties. Rev. Mineral. Geochem. 32, 505-561.

Wondraczek, L., and Behrens, H. (2007). Molar volume, excess enthalpy, and Prigogine-Defay ratio of some silicate glasses with different $(\mathrm{P}, \mathrm{T})$ histories. J. Chem. Phys. 127, 154503. doi:10.1063/1.2794745

Wondraczek, L., Behrens, H., Yue, Y., Deubener, J., and Scherer, G. W. (2007a). Relaxation and glass transition in an isostatically compressed diopside glass. J. Am. Ceram. Soc 90, 1556-1561. doi:10.1111/j.1551-2916.2007. 01566.x

Wondraczek, L., Sen, S., Behrens, H., and Youngman, R. E. (2007b). Structureenergy map of alkali borosilicate glasses: effects of pressure and temperature. Phys. Rev. B 76, 014202. doi:10.1103/PhysRevB.76.014202

Wondraczek, L., Krolikowski, S., and Behrens, H. (2010). Kinetics of pressure relaxation in a compressed alkali borosilicate glass. J. Non Cryst. Solids 356, 1859-1862. doi:10.1016/j.jnoncrysol.2010.06.009

Wondraczek, L., and Mauro, J.C. (2009). Advancing glasses through fundamental research. J. Eur. Ceram. Soc. 29, 1227-1234. doi:10.1016/ j.jeurceramsoc.2008.08.006

Wondraczek, L., Mauro, J. C., Eckert, J., Kühn, U., Horbach, J., Deubener, J., et al. (2011). Towards ultrastrong glasses. Adv. Mater. 23, 4578-4586. doi:10.1002/ adma.201102795

Wright, A. C., Stone, C. E., Sinclair, R. N., Umesaki, N., Kitamura, N., Ura, K., et al. (2000). Structure of pressure compacted vitreous boron oxide. Phys. Chem. Glasses 41, 296-299.

Wu, J., Deubener, J., Stebbins, J. F., Grygarova, L., Behrens, H., Wondraczek, L., et al. (2009). Structural response of a highly viscous aluminoborosilicate melt to isotropic and anisotropic compressions. J. Chem. Phys. 131, 104504. doi: $10.1063 / 1.3223282$

Wu, J., and Stebbins, J. F. (2009). Effects of cation field strength on the structure of aluminoborosilicate glasses: high-resolution ${ }^{11} \mathrm{~B},{ }^{27} \mathrm{Al}$ and ${ }^{23} \mathrm{Na}$ MAS NMR. J. Non Cryst. Solids 355, 556-562. doi:10.1016/j.jnoncrysol.2009.01.025 
Wüllen, L. V., Tricot, G., and Wegner, S. (2007). An advanced NMR protocol for the structural characterization of aluminophosphate glasses. Solid State Nucl. Magn. Reson. 32, 44-52. doi:10.1016/j.ssnmr.2007. 07.004

Xue, X., Kanzaki, M., Tronnes, R. G., and Stebbins, J. F. (1989). Silicon coordination and speciation changes in a silicate liquid at high pressures. Science 245, 962-964. doi:10.1126/science.245.4921.962

Xue, X., and Stebbins, J. F. (1993). ${ }^{23} \mathrm{Na}$ NMR chemical shifts and local Na coordination environments in silicate crystals, melts and glasses. Phys. Chem. Miner. 20, 297-307. doi:10.1007/BF00215100

Yamada, A., Gaudio, S. J., and Lesher, C. E. (2010). Densification of $\mathrm{MgSiO}_{3}$ glass with pressure and temperature. J. Phys. 215, 012085. doi:10.1088/ 1742-6596/215/1/012085

Yarger, J. L., Smith, K. H., Nieman, R. A., Diefenbacher, J., Wolf, G. H., Poe, B. T., et al. (1995). Al coordination changes in high-pressure aluminosilicate liquids. Science 270, 1964. doi:10.1126/science.270.5244.1964

Yoshimoto, M., Soga, N., Hirao, K., and Yamamoto, H. (1989). Effects of densification on mechanical properties of lead silicate glasses. J. Ceram. Soc. Jpn. 97, 1446-1450. doi:10.2109/jcersj.97.1446

Youngman, R. E., Haubrich, S. T., Zwanziger, J. W., Janicke, M. T., and Chmelka, B. E. (1995). Short- and intermediate-range structural ordering in glassy boron oxide. Science 269, 1416. doi:10.1126/science.269.5229.1416

Yue, Y., Wondraczek, L., Behrens, H., and Deubener, J. (2007). Glass transition in an isostatically compressed calcium metaphosphate glass. J. Chem. Phys. 126, 144902. doi:10.1063/1.2719194

Zhang, L., Eckert, H., Helsch, G., and Frischat, G. (2005). Network modification of glassy $\mathrm{AlPO}_{4}$ : sol-gel synthesis and structural characterization of the system $\mathrm{Na}_{2} \mathrm{O}-\mathrm{AlPO}_{4}$ Z. Phys. Chem. 219, 71-87. doi:10.1524/zpch.219.1.71. 55020

Zhang, P., Grandinetti, P. J., and Stebbins, J. F. (1997). Anionic species determination in $\mathrm{CaSiO}_{3}$ glass using two-dimensional ${ }^{29} \mathrm{Si} \mathrm{NMR}$. J. Phys. Chem. B 101, 4004-4008. doi:10.1021/jp9700342

Zhang, Z., Hirao, K., and Soga, N. (1991a). Water corrosion behavior of densified glass. II. Borate glasses. J. Non Cryst. Solids 135, 62-66. doi:10.1016/0022-3093(91)90443-A

Zhang, Z., Soga, N., and Hirao, K. (1991b). Water corrosion behavior of densified glass. I. Silicate glass. J. Non Cryst. Solids 135, 55-61. doi:10.1016/0022-3093(91)90442-9

Zhang, Z., and Soga, N. (1991). Structural study of densified borate glasses by Raman and infrared spectroscopy. Phys. Chem. Glasses 32, 142-148.

Zhang, Z., Soga, N., and Hirao, K. (1995). Indentation deformation and fracture of densified silicate glass. J. Mater. Sci. 30, 6359-6362. doi:10.1007/ BF00369689

Conflict of Interest Statement: The authors declare that the research was conducted in the absence of any commercial or financial relationships that could be construed as a potential conflict of interest.

Copyright $\odot 2017$ Kapoor, Wondraczek and Smedskjaer. This is an open-access article distributed under the terms of the Creative Commons Attribution License (CC BY). The use, distribution or reproduction in other forums is permitted, provided the original author(s) or licensor are credited and that the original publication in this journal is cited, in accordance with accepted academic practice. No use, distribution or reproduction is permitted which does not comply with these terms. 